\title{
Dynamic Macrophage "Probing" Is Required For The Efficient Capture Of Phagocytic Targets
}

\section{Citation}

Flannagan, Ronald S., Rene E. Harrison, Christopher M. Yip, Khuloud Jaqaman, and Sergio Grinstein. 2010. Dynamic macrophage "probing" is required for the efficient capture of phagocytic targets. The Journal of Cell Biology 191(6): 1205-1218.

\section{Published Version}

doi://10.1083/jcb.201007056

\section{Permanent link}

http://nrs.harvard.edu/urn-3:HUL.InstRepos:5360621

\section{Terms of Use}

This article was downloaded from Harvard University's DASH repository, and is made available under the terms and conditions applicable to Other Posted Material, as set forth at http:// nrs.harvard.edu/urn-3:HUL.InstRepos:dash.current.terms-of-use\#LAA

\section{Share Your Story}

The Harvard community has made this article openly available.

Please share how this access benefits you. Submit a story.

\section{Accessibility}




\title{
Dynamic macrophage "probing" is required for the efficient capture of phagocytic targets
}

\author{
Ronald S. Flannagan, ${ }^{1}$ Rene E. Harrison, ${ }^{2}$ Christopher M. Yip, ${ }^{3}$ Khuloud Jaqaman, ${ }^{4}$ and Sergio Grinstein ${ }^{1}$ \\ 'Program in Cell Biology, Hospital for Sick Children, Toronto, Ontario M5G 1X8, Canada \\ 2Department of Biological Sciences, University of Toronto Scarborough, Toronto, Ontario M1C 1A4, Canada \\ ${ }^{3}$ Institute of Biomaterials and Biomedical Engineering, Terrence Donnelly Centre for Cellular and Biomolecular Research, University of Toronto, Toronto, \\ Ontario M5S 3E 1, Canada \\ ${ }^{4}$ Department of Systems Biology, Harvard Medical School, Boston, MA 02115
}

B inding of ligands by immunoreceptors is thought to be a passive, stochastic process. Contrary to this notion, we found that binding of IgG-opsonized particles by Fcy receptors was inhibited in macrophages, dendritic and microglial cells by agents that interfere with actin assembly or disassembly. Changes in the lateral mobility of the receptors-assessed by single-particle tracking-or in the microelasticity of the membranedetermined by atomic-force microscopy-could not account for the effects of actin disruption on particle binding. Instead, we found that the macrophages contact their targets by actively extending actin-rich structures. Formation of these protrusions is driven by Rac and requires phosphatidylinositol 4,5-bisphosphate and phosphatidylinositol 3,4,5-trisphosphate. Capture of C3bi-opsonized as well as unopsonized targets by macrophages was also dependent on actin. Thus, phagocytes continuously probe their environment for foreign particles in a manner akin to the constitutive sampling of the fluid milieu by dendritic cells. Active probing by phagocytes is most important when confronted by scarcely opsonized and/or highly mobile targets.

\section{Introduction}

The ability of macrophages to engulf large $(>0.5 \mu \mathrm{m})$ particulate targets by phagocytosis is central to both the innate and adaptive immune responses (Greenberg and Grinstein, 2002). Phagocytosis is initiated upon ligation of surface receptors like the widely studied $\mathrm{Fc} \gamma$ receptor $(\mathrm{Fc} \gamma \mathrm{R})$, which recognizes the $\mathrm{Fc}$ region of $\mathrm{IgG}$ to trigger internalization of opsonized matter, such as pathogenic microbes. Engagement of Fc $\gamma$ Rs elicits tyrosine phosphorylation-dependent signaling events that cause profound cellular changes characterized by coordinated actin polymerization, the elaboration of pseudopods, and ultimately the ingestion of the target into a membrane-bound vacuole termed the phagosome (Flannagan et al., 2009).

Much has been learned about the signals that lead to actin remodelling. Generation of phosphatidylinositol 3,4,5trisphosphate $\left(\mathrm{PI}(3,4,5) \mathrm{P}_{3}\right)$ and metabolism of phosphatidylinositol 4,5-bisphosphate $\left(\mathrm{PI}(4,5) \mathrm{P}_{2}\right)$ are critical early events

Correspondence to Sergio Grinstein: sergio.grinstein@sickkids.ca

Abbreviations used in this paper: $\mathrm{Fc} \gamma \mathrm{R}, \mathrm{Fc} \gamma$ receptor; $\mathrm{PI}(3,4,5) \mathrm{P}_{3}$, phosphatidylinositol 3,4,5-trisphosphate; $\mathrm{PI}(4,5) \mathrm{P}_{2}$, phosphatidylinositol 4,5-bisphosphate; PM-GFP, palmitoylated/myristoylated-tagged GFP; SPT, single-particle tracking; $S R B C$, sheep red blood cell; TIR-FM, total internal reflection fluorescence microscopy.
(Botelho et al., 2000; Marshall et al., 2001; Scott et al., 2005). In addition, tyrosine phosphorylation triggers the activation of Rac and Cdc42, which direct actin polymerization via SCAR/ WAVE, WASP, and Arp2/3 (May et al., 2000; Hoppe and Swanson, 2004). By contrast, much less is known about the early events that dictate the binding of the phagocytic target. It has been tacitly assumed that particle binding is a passive event, driven by lateral diffusion of the Fc $\gamma$ Rs in the plane of the plasma membrane (Michl et al., 1983). In accordance with this model, treatment of macrophages with jasplakinolide, an F-actin-stabilizing agent, greatly reduced particle binding, ostensibly by limiting the lateral mobility of the receptors (Mao et al., 2009). A similar explanation was offered to account for the effect of 4-phosphatidylinositol 5-kinase gamma (PIP5K $\gamma$ ) deletion, which also impaired particle attachment (Mao et al., 2009).

In this manuscript we used single-particle tracking (SPT) to test experimentally the assumption that Fc $\gamma$ Rs diffuse freely in the fluid mosaic of the plasma membrane and that F-actin

(C) 2010 Flannagan et al. This article is distributed under the terms of an AttributionNoncommercial-Share Alike-No Mirror Sites license for the first six months after the publication date (see http://www.rupress.org/terms). After six months it is available under a Creative Commons License (Attribution-Noncommercial-Share Alike 3.0 Unported license, as described at http://creativecommons.org/licenses/by-nc-sa/3.0/). 
stabilization limits their mobility, thereby curtailing particle binding. Our results are inconsistent with this model and revealed instead that actin-driven active "probing" of the environment by the cells in a direction perpendicular to the plane of the membrane is critical to secure targets to the surface of the phagocyte. This unappreciated behavior is in part regulated by Rac, $\mathrm{PI}(4,5) \mathrm{P}_{2}$, and $\mathrm{PI}(3,4,5) \mathrm{P}_{3}$, all of which are required for optimal binding.

\section{Results}

Actin perturbation impairs the capture of IgG-opsonized phagocytic targets

To verify the effect of increased actin polymerization on particle binding we treated RAW264.7 macrophages (called RAW hereafter) with jasplakinolide before the addition of IgGopsonized latex beads. As reported (Mao et al., 2009), jasplakinolide drastically reduced the number of particles associated with the macrophages (78\% inhibition; Fig. 1 B). However, microscopic visualization of the cells revealed that the drug induced gross morphological changes, notably the emergence of large membrane blebs (Fig. 1 A). The drastic change in cell shape may have altered the ability of the receptors to interact with their targets. We hypothesized that blebbing resulted from the contraction of stabilized F-actin filaments, a process likely driven by myosin II. We therefore tested the effect of blebbistatin, a selective myosin IIa inhibitor (Kovács et al., 2004). By itself blebbistatin had only modest effects on cell shape but, remarkably, it eliminated the blebbing caused by jasplakinolide (Fig. 1 A). In parallel, blebbistatin prevented the submembranous compaction of actin caused by jasplakinolide, as revealed by visualization of GFP-actin in stably transfected cells (Fig. 1 A, bottom panels). Under these conditions jasplakinolide still bound to F-actin, as judged by its ability to prevent the binding of labeled phalloidin (not depicted). These observations confirmed that myosin-induced contraction is required for the blebbing caused by jasplakinolide and, more importantly, provided a means of testing the effects of actin stabilization on particle binding, uncontaminated by untoward shape changes. Although blebbistatin restored the normal shape of jasplakinolide-treated cells, it failed to prevent the inhibition of particle binding (Fig. $1 \mathrm{~B}$ ). Therefore, impairment of binding was caused by stabilization of F-actin, independently of the blebbing that accompanies actin compaction when myosin is functional.

\section{Altered behavior of Fcy receptors does not explain jasplakinolide-induced binding defects}

The comparatively low affinity of Fc $\gamma \mathrm{R}$ for the Fc portion of $\mathrm{IgG}$ requires the formation of multiple receptor-ligand complexes to provide sufficient avidity to secure a target particle to the macrophage surface. The reduced binding of IgG-coated targets caused by jasplakinolide can therefore be envisaged to result from impaired lateral mobility of Fc $\gamma \mathrm{R}$ or, more simply, from reduced receptor density at the membrane that may have resulted from endocytosis or shedding. We used receptorspecific antibodies and flow cytometry to quantify the surface expression of Fc $\gamma$ RI, II, and III; neither jasplakinolide alone, nor the combined treatment with jasplakinolide and blebbistatin altered the density of Fc $\gamma \mathrm{R}$ on the surface of RAW cells (Fig. 1, $\mathrm{C}$ and $\mathrm{D})$. The ability of the receptors to engage the Fc portion of IgG was similarly unaffected. This was verified by measuring the ability of the cells to bind soluble IgG aggregates (agIgG). Such experiments, which were performed at $15^{\circ} \mathrm{C}$ to prevent endocytosis, demonstrated that agIgG bound to a similar extent to control and jasplakinolide- or jasplakinolide plus blebbistatintreated cells (Fig. 1, E and F). Furthermore, analysis by immunoblotting revealed that, irrespective of drug treatment, binding of agIgG increased the abundance of tyrosine-phosphorylated proteins to a similar degree (not depicted). Together, these experiments indicate that jasplakinolide affects neither the number of surface receptors, nor their ability to bind IgG.

Next we hypothesized that jasplakinolide inhibits particle binding by restricting the lateral mobility of Fc $\gamma$ Rs, thereby preventing their coalescence into high avidity clusters. Single-particle tracking (SPT) was used to analyze the mobility of individual receptors in the plane of the membrane. To avoid cross-linking, we generated antigen-binding fragments (Fab) from the 2.4G2 primary antibody, which were in turn labeled with biotinylated secondary Fab fragments coupled to Quantum dots. Preliminary experiments demonstrated that the $2.4 \mathrm{G} 2 \mathrm{Fab}$ fragments retained specificity for Fc $\gamma$ RII/III and that under the conditions used, single receptors and not higher order complexes, were tracked (Fig. S1, A and B). This system was used to test the notion that Fc $\gamma$ Rs diffuse freely on the plane of the membrane and that stiffening the submembranous F-actin network with jasplakinolide reduces their mobility. As shown in Fig. 2, these predictions were not borne out by the measurements. First, even in untreated cells a large fraction $(71.2 \%)$ of the Fc $\gamma$ RII/III demonstrated restricted diffusion (Fig. 2, A and B), moving within a confinement area of $0.11 \mu^{2}$. The diffusion coefficient of the particles displaying confined diffusion was significantly smaller than that of particles diffusing in an unrestricted manner (Fig. 2 D). More importantly, treatment with jasplakinolide, whether with or without blebbistatin, had little effect on the fraction of restricted versus unrestricted receptors (Fig. 2 B) and a modest effect on the diffusion coefficient. In fact, the diffusion coefficient increased in the presence of jasplakinolide, although this change was not statistically significant (Fig. 2 D).

The mobility of the high affinity receptor, Fc $\gamma$ RI, was also analyzed by SPT. Because the affinity of Fab fragments generated from Fc $\gamma$ RI-specific antibodies was insufficient for proper labeling, intact antibodies were used for these experiments. Although dimers may have formed upon addition of the antibodies, the labeling procedure did not induce receptor internalization because $>98 \%$ of the probe was removed by an acute acid wash at the end of the experiment. As found for FcyRII/III, a sizable fraction of Fc $\gamma$ RI diffused in a restricted manner within confinement areas and this feature was unaffected by jasplakinolide (Fig. 2 C). Similarly, the actin-stabilizing agent had little effect on the diffusion coefficient of either the restricted or unrestricted Fc $\gamma$ RI receptors (Fig. 2 D). Therefore, the inhibitory effects of jasplakinolide on particle binding cannot be simply accounted for by altered Fc $\gamma \mathrm{R}$ mobility in the plane of the membrane. 
A
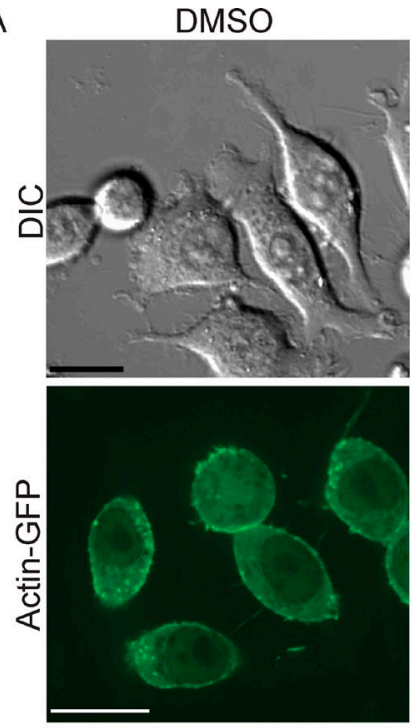

B 140

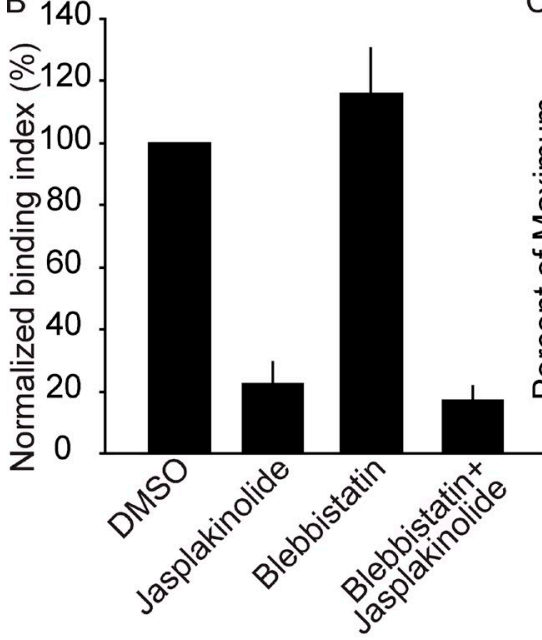

Jasplakinolide
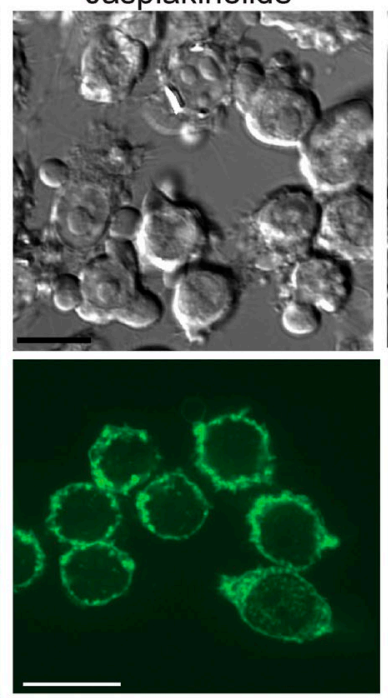

C

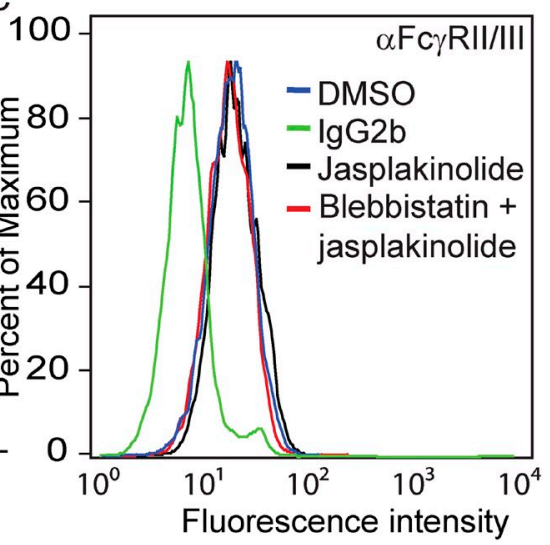

Blebbistatin + Jasp
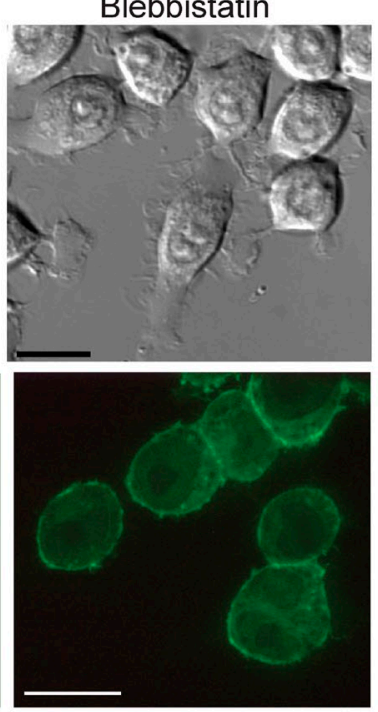

D
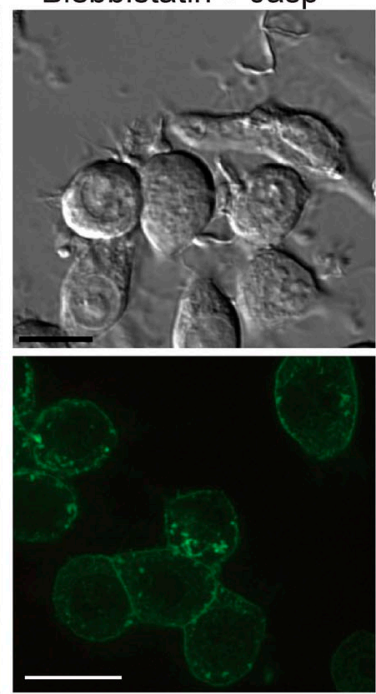

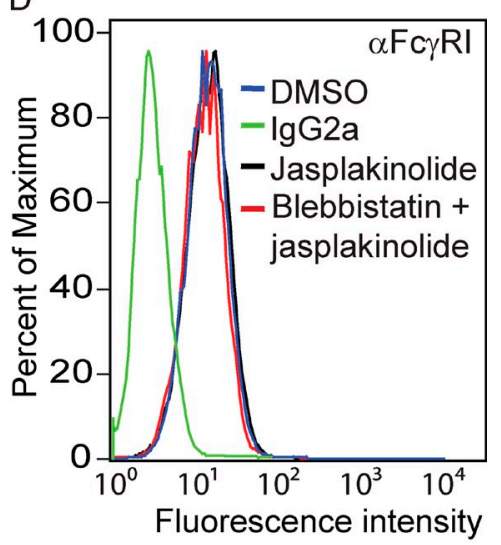

E

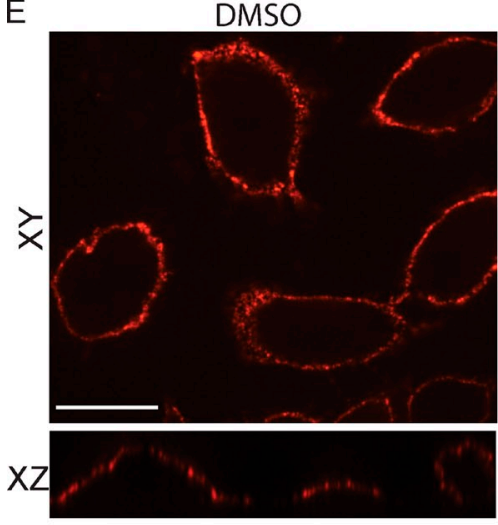

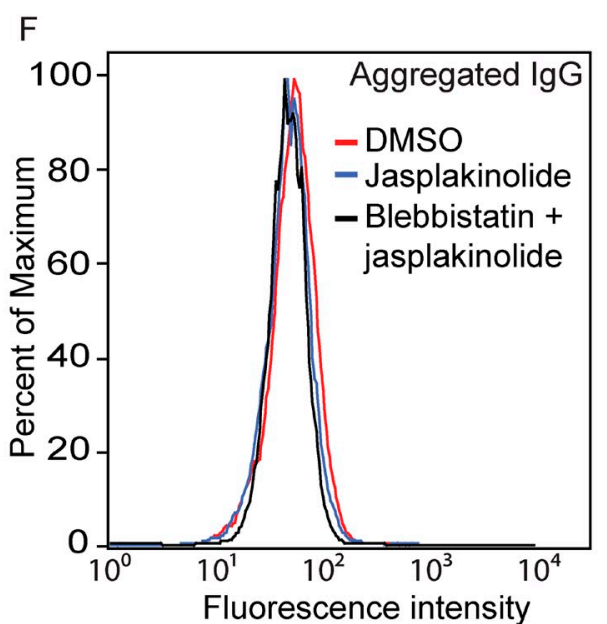

Figure 1. Actin-perturbing drugs alter the binding of IgG-opsonized particles. (A) Representative differential interference contrast (DIC, top panels) and spinning-disk confocal fluorescence images (bottom panels) of RAW cells stably expressing actin-GFP. Where indicated the cells were treated with $1 \mu M$ jasplakinolide, $0.2 \mu \mathrm{M}$ latrunculin, and/or $60 \mu \mathrm{M}$ blebbistatin. DMSO was used as vehicle. Bars: $8 \mu \mathrm{m}$ (top panels), $17 \mu \mathrm{m}$ (bottom panels). (B) Quantitation of the effect of actin-perturbing drugs on particle binding. Data are presented as a binding index (see Materials and methods) normalized to the vehicle control and are means \pm SEM of three experiments, each counting at least 150 macrophages per condition. (C and D) Surface expression of FcyRll/III (C) and FcyRI (D), measured by flow cytometry after pretreatment with actin-perturbing agents or vehicle only. (E) Binding of soluble lgG aggregates to RAW macrophages at $15^{\circ} \mathrm{C}$. Representative $x y$ and $x z$ optical slices obtained by spinning-disk microscopy are illustrated; bar, $17 \mu \mathrm{m}$. Surface-associated lgG aggregates were detected using a Cy3-conjugated secondary antibody. (F) Quantification of surface-associated lgG in cells treated with actin-perturbing agents. Following labeling as in $\mathrm{E}$, the cells were detached from the substratum, fixed, and analyzed by flow cytometry. Histograms in C-E are representative of two independent experiments of each type. 
A

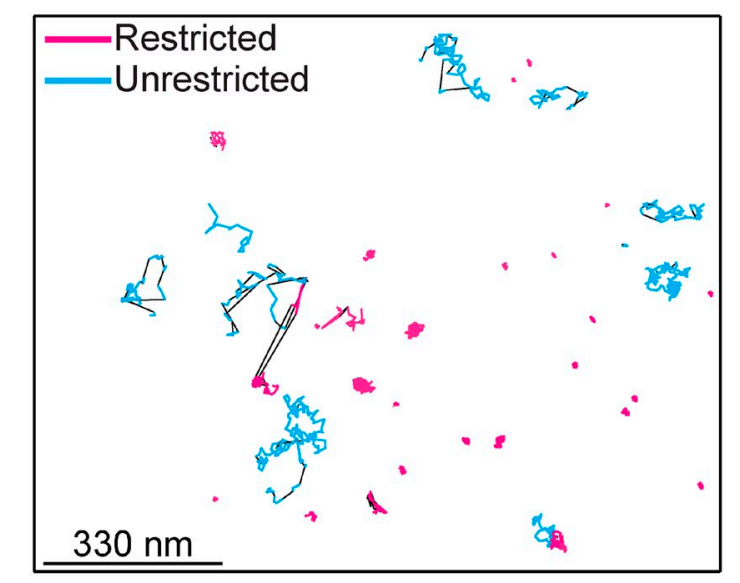

C

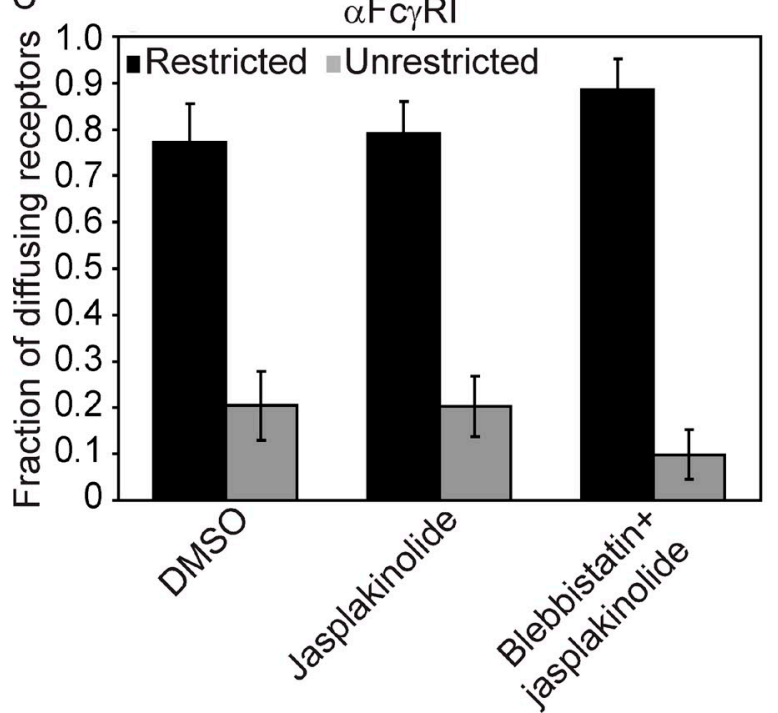

B

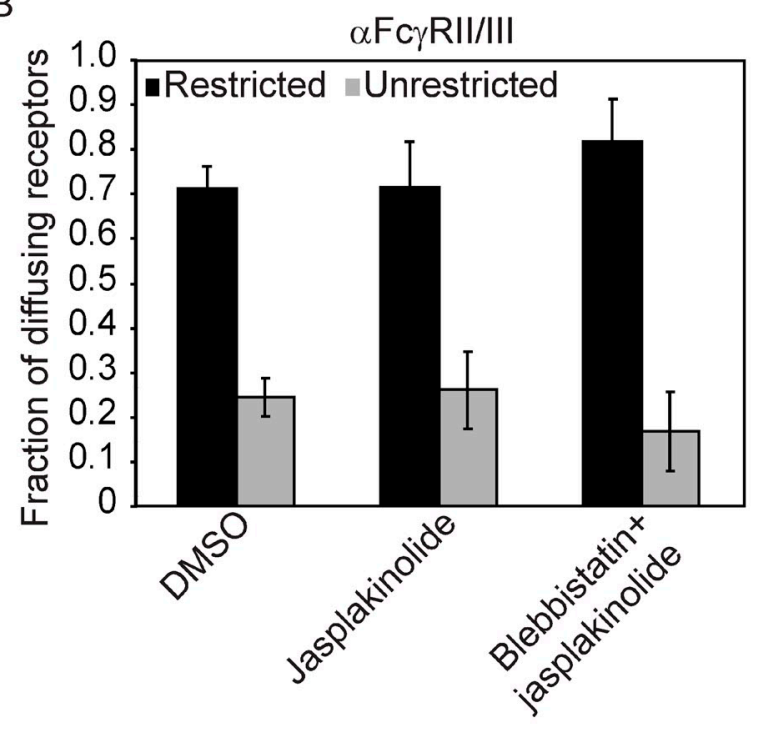

D

Diffusion coefficient $\left(\mu \mathrm{m}^{2} / \mathrm{sec}\right)$

\begin{tabular}{|c|c|c|}
\hline $\mathrm{Fc} \gamma \mathrm{RII} / \mathrm{II}$ & Restricted & Unrestricted \\
\hline DMSO & $0.020 \pm 0.0025$ & $0.034 \pm 0.0039$ \\
\hline Jasplakinolide & $0.023 \pm 0.0060$ & $0.051 \pm 0.0116$ \\
\hline $\begin{array}{l}\text { Blebbistatin + } \\
\text { jasplakinolide }\end{array}$ & $0.014 \pm 0.0030$ & $0.027 \pm 0.0122$ \\
\hline \multicolumn{3}{|l|}{$\mathrm{Fc \gamma RI}$} \\
\hline$\overline{\mathrm{DMSO}}$ & $0.028 \pm 0.0035$ & $0.052 \pm 0.0111$ \\
\hline Jasplakinolide & $0.021 \pm 0.0036$ & $0.046 \pm 0.0266$ \\
\hline $\begin{array}{l}\text { Blebbistatin + } \\
\text { jasplakinolide }\end{array}$ & $0.015 \pm 0.0062$ & $0.032 \pm 0.0181$ \\
\hline
\end{tabular}

Figure 2. Effect of actin perturbation on the mobility of mouse FcyR, determined by single-particle tracking (SPT). (A) Representative tracks of FcyRII/III, labeled under control conditions using primary Fab fragments and detected with quantum dots, as described in Materials and methods. All tracks were obtained from $\geq 20$-s movies with an image acquisition rate of $33 \mathrm{~Hz}$. The motion type was determined by moment scaling spectrum analysis and only tracks of at least 20 frames were analyzed (see Materials and methods). The cyan lines in A indicate tracks of FcyR with unrestricted diffusion, whereas the pink lines indicate tracks classified as restricted by the SPT software. The black lines in A indicate the closing of gaps as performed by the SPT software. Tracking of receptors in jasplakinolide-treated cells was limited to areas of the plasma membrane devoid of blebs. (B and C) Percentage of FcyRll/III (B) and FcyRI (C) tracked receptors undergoing either restricted or unrestricted diffusion under control or drug-treated conditions. (D) Summary of the calculated diffusion coefficients for FcyRl and FcyRlI/III tracked in macrophages pretreated with vehicle (DMSO) or actin-perturbing agents. Data in B-D are means \pm SEM of three independent experiments, with at least 10 cells analyzed per condition per experiment.

Plasma membrane microelasticity and its effect on the binding of phagocytic targets Because neither the density, mobility, nor the ability of Fc $\gamma \mathrm{R}$ to recognize ligands explained the inhibitory effects of jasplakinolide, we wondered whether the drug acts by altering the biophysical properties of the plasma membrane. Specifically, we questioned whether increased rigidity prevents the phagocyte membrane from effectively apposing the target particle, which is likely required to enable a sufficient number of receptors to contact their ligand. Indeed, in other cell types jasplakinolide has been shown to reduce the microelasticity of the plasma membrane (Sheikh et al., 1997). We used atomic force microscopy (AFM) to test whether the F-actin stabilizer exerts a comparable effect on macrophages. Measurements of tip deflection when applying force on the dorsal surface of the cells indicated that, as in other cells, jasplakinolide increases membrane rigidity in macrophages (Fig. 3, A and B).

The increased rigidity caused by jasplakinolide could in principle account for the impaired ability of the macrophages to engage a sufficient number of receptors to secure their targets. If correct, this notion predicts that opposite effects should be obtained when membrane rigidity is decreased. This prediction was tested using latrunculin $\mathrm{B}$, an effective actin-depolymerizing agent. We used only short ( $8 \mathrm{~min}$ ) latrunculin treatments that yield incomplete depolymerization of the submembranous actin to limit extreme changes in shape and detachment of the cells from the substratum (Fig. 3 C). As illustrated in Fig. 3 C, cells treated with the actin-depolymerizing drug underwent visible 

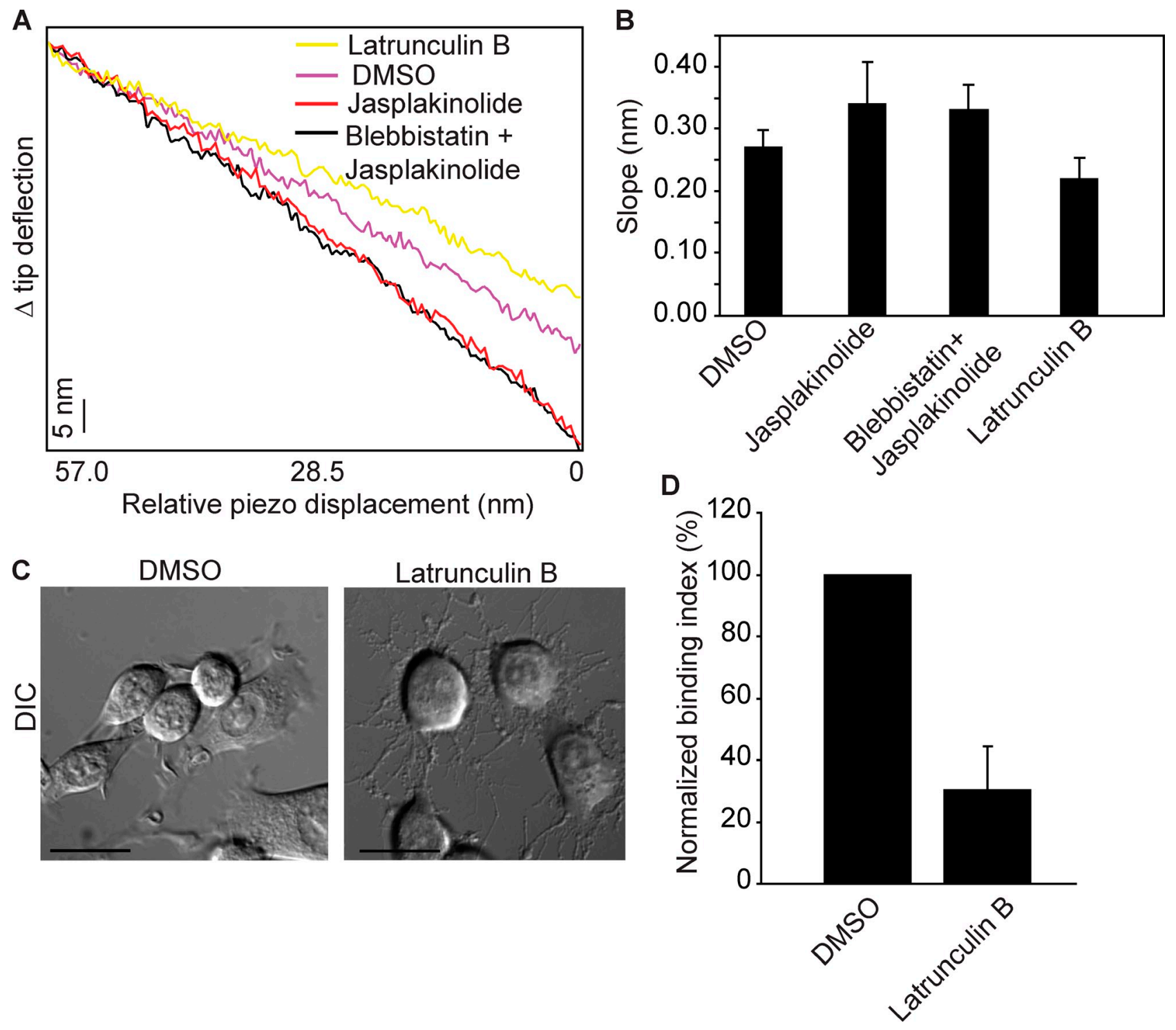

Figure 3. Effect of actin perturbation on membrane microelasticity and ability to capture IgG-opsonized particles. (A and B) The microelasticity of the membrane of control or drug-treated RAW cells was assessed by atomic force microscopy. Representative force curves illustrating the deflection of the cantilever after contact with the cell surface are shown in A and quantitation of multiple force curves in B. Data in B are mean slopes \pm SEM obtained probing a minimum of 15 individual cells at 3 distinct sites/cell, from three independent experiments. (C) Representative DIC images depicting the morphology of control and latrunculin B-treated RAW macrophages; bar, $18 \mu \mathrm{m}$. (D) Quantitation of the effect of latrunculin B on particle binding. Data are presented as a binding index normalized to the vehicle control and are means \pm SEM of three experiments, each counting at least 150 macrophages per condition.

morphological changes and, as anticipated, their rigidity measured by AFM decreased (Fig. 3, A and B). Contrary to expectations, however, the ability of latrunculin-treated cells to bind IgG-opsonized latex beads decreased greatly, despite their more flexible membrane (Fig. 3 D). Flow cytometry and immunoblotting experiments like those described above confirmed that the number of FcyRs at the surface and their ability to bind and be stimulated by soluble agIgG remained unaltered in latrunculintreated cells (Fig. S2; and unpublished data).

The mobility of Fc $\gamma \mathrm{R}$ in cells treated with latrunculin was also analyzed, using SPT. Analysis of Fc $\gamma$ RI revealed a $15 \%$ decrease in the fraction of diffusion-restricted receptors, with a concomitant increase in freely diffusible ones (Fig. S3 B). The diffusion coefficients of both subpopulations increased, from 0.0276 and $0.0523 \mu \mathrm{m}^{2} / \mathrm{s}$ to 0.0384 and $0.0768 \mu \mathrm{m}^{2} / \mathrm{s}$, respectively
(Fig. S3 C). A reproducible and significant increase in the diffusion coefficients of FcyRII/III was also recorded (Fig. S3 C), though the ratio of confined to freely mobile receptors was not altered when using $2 \mu \mathrm{M}$ latrunculin B for 8 min (Fig. S3 A), likely because the mild conditions used resulted only in partial actin disruption. Accordingly, more rigorous treatment with latrunculin (4 $\mu \mathrm{M}$ for $20 \mathrm{~min}$ ) reduced the fraction of Fc $\gamma \mathrm{RII} / \mathrm{III}$ diffusing in a restricted manner, while concomitantly increasing the fraction displaying unrestricted diffusion, although these changes did not reach statistical significance (Fig. S3 A). These observations demonstrate that the diffusion of $\mathrm{Fc} \gamma \mathrm{R}$ is influenced by actin, though other factors, such as plasma membrane protein density, likely also limit receptor mobility (Frick et al., 2007). Regardless of their magnitude, the changes in receptor mobility failed to account for the profound inhibition of binding caused by latrunculin. 
Dynamic membrane protrusions bind phagocytic targets

Taken together with the jasplakinolide observations, the effects of latrunculin ruled out changes in receptor mobility or in membrane rigidity as the cause of the impaired particle binding induced by interference with normal actin function. Because both actin-stabilizing and -depolymerizing drugs impaired particle binding, we hypothesized that a dynamic actin-dependent process was involved in optimal receptor engagement. Specifically, we explored whether Fc $\gamma$ Rs are driven toward their ligands by an active process involving actin-mediated protrusion or contraction. Light microscopy of RAW cells revealed that the macrophages are constitutively active, continuously elaborating and retracting ruffles and filopodia (Video 1). Of note, immunolabeling experiments preformed on live cells revealed that Fc $\gamma \mathrm{R}$ is present in these dynamic structures at a density comparable to that in the bulk plasma membrane (Fig. S4). Because this dynamic behavior is ablated by jasplakinolide or latrunculin (unpublished data), we considered whether "probing" of the environment by these protrusions is involved in optimal Fc $\gamma \mathrm{R}$ binding. To quantitatively assess the spontaneous extension of protrusions we used total interference reflection fluorescence microscopy (TIR-FM). Macrophages stably transfected with glycophosphatidylinositol (GPI)-linked GFP, where the fluorescent protein is exofacial, were suspended and allowed to settle onto a BSA-coated coverslip. Extensions of the membrane that made contact with or closely approached the coverslip became readily apparent by TIR-FM (Fig. 4 A and Video 2). Notably, these membrane protrusions repeatedly retracted and reappeared, indicating that they are dynamic. Integration of the area engaged over time demonstrated that this behavior occurs continuously (Fig. 4 B). The extensions are driven by actin remodelling because they were largely eliminated by jasplakinolide or latrunculin (Fig. 4 B and Video 3).

$\mathrm{IgG}$ was omitted from the preceding experiments to demonstrate that the extension of protrusions occurs constitutively, in the absence of phagocytic ligands. When the surface of the coverslip was coated with IgG the spontaneous membrane extensions engaged the opsonin but failed to retract, resulting in an explosive spreading, a form of "frustrated phagocytosis" (Video 4).

Scanning electron microscopy (SEM) was used to better visualize the protrusions that are involved in the early stages of engagement of phagocytic targets by macrophages. When the interaction between cells and IgG-opsonized beads was arrested at a very early stage, before development of phagocytic cups, the association of fine filopodia and membrane ruffles with the targets were readily apparent (Fig. 4, C and D). Of note, even when particles settled by gravity onto latrunculin- or jasplakinolidetreated cells, such attachments were absent (Fig. 4 E). We therefore assumed that active probing by actin-induced filopodia and ruffles enabled a sufficient number of receptors to become engaged, securing the particles and preventing their removal upon subsequent washing. That retentive forces developed as a result of the actin-driven protrusions was validated using optical tweezers. IgG-opsonized sheep red blood cells (sRBCs), which were easily trapped by the laser beam, were positioned and held in proximity to RAW macrophages, without making contact with the bulk plasma membrane. At defined time intervals, the position of the laser trap was altered and the ability to remove the sRBCs from the vicinity of the phagocyte was assessed (Fig. 4 F). Importantly, because the targets were positioned at a short distance $(\sim 1 \mu \mathrm{m})$ away from the membrane surface, the cells could make contact with the sRBCs only by extension of membrane protrusions. Indeed, thin projections making contact with the phagocytic targets often became apparent when attempting to remove the sRBCs from control macrophages (Fig. $4 \mathrm{~F}$ ). In every instance, untreated macrophages engaged the sRBCs within $30 \mathrm{~s}$ with sufficient force to displace them from the optical trap (Fig. 4 G). In stark contrast, cells treated with either latrunculin B or jasplakinolide plus blebbistatin were unable to retain the sRBCs, which were successfully removed by the trap even after $150 \mathrm{~s}$ (Fig. 4 G). Furthermore, sRBCs placed in direct contact with the bulk plasma membrane of drug-treated cells could be readily removed from cells through manipulation of the optical trap, indicating the necessity of this behavior for binding (not depicted). These findings indicate that dynamic actin-induced structures secure particles to the surface of phagocytes by increasing the strength of the interaction, in all likelihood by facilitating the formation of a larger number of receptor-ligand complexes.

Membrane protrusions promote the capture of diverse phagocytic targets and are used by various phagocytic cell types The inhibitory effects of jasplakinolide and latrunculin on the capture of phagocytic targets are not unique to RAW macrophages, nor are they an exclusive feature of immortalized cells in culture. Primary macrophages isolated from the bone marrow of mice displayed a similar behavior, with $>90 \%$ inhibition in jasplakinolide- or latrunculin-treated cells compared with untreated controls (Fig. 5 B). Similarly, binding of IgG-coated particles was severely impaired $(>95 \%)$ by latrunculin in primary CD11c-positive dendritic cells that were primed with lipopolysaccharide to enhance their adherence to glass coverslips (Fig. 5 C; see Materials and methods for details). Lastly, microglial (BV2) cells were also tested. As shown in Fig. 5 D, actin perturbation depressed particle binding by $\sim 85 \%$ in these cells. Interestingly, stimulation with the protein kinase $\mathrm{C}$ agonist phorbol 12-myristate 13acetate (PMA; $100 \mathrm{nM}$ for $5 \mathrm{~min}$ ), which induced the formation of large dorsal ruffles (not depicted), enhanced the capacity of BV2 cells to capture IgG-opsonized particles, and the additional binding was also ablated by treatment with latrunculin B (Fig. 5 D).

To determine whether the formation of membrane protrusions was required for the capture of targets bearing ligands other than $\mathrm{IgG}$, we tested the effects of latrunculin on the binding of C3bi-opsonized sRBCs and of unopsonized zymosan by RAW macrophages. Pre-treatment with latrunculin drastically impaired the capture of C3bi-opsonized sRBCs relative to control cells (Fig. 5 A). Likewise, treatment with latrunculin also depressed the ability of RAW cells to secure unopsonized zymosan, which is mediated by receptors to microbial-associated 

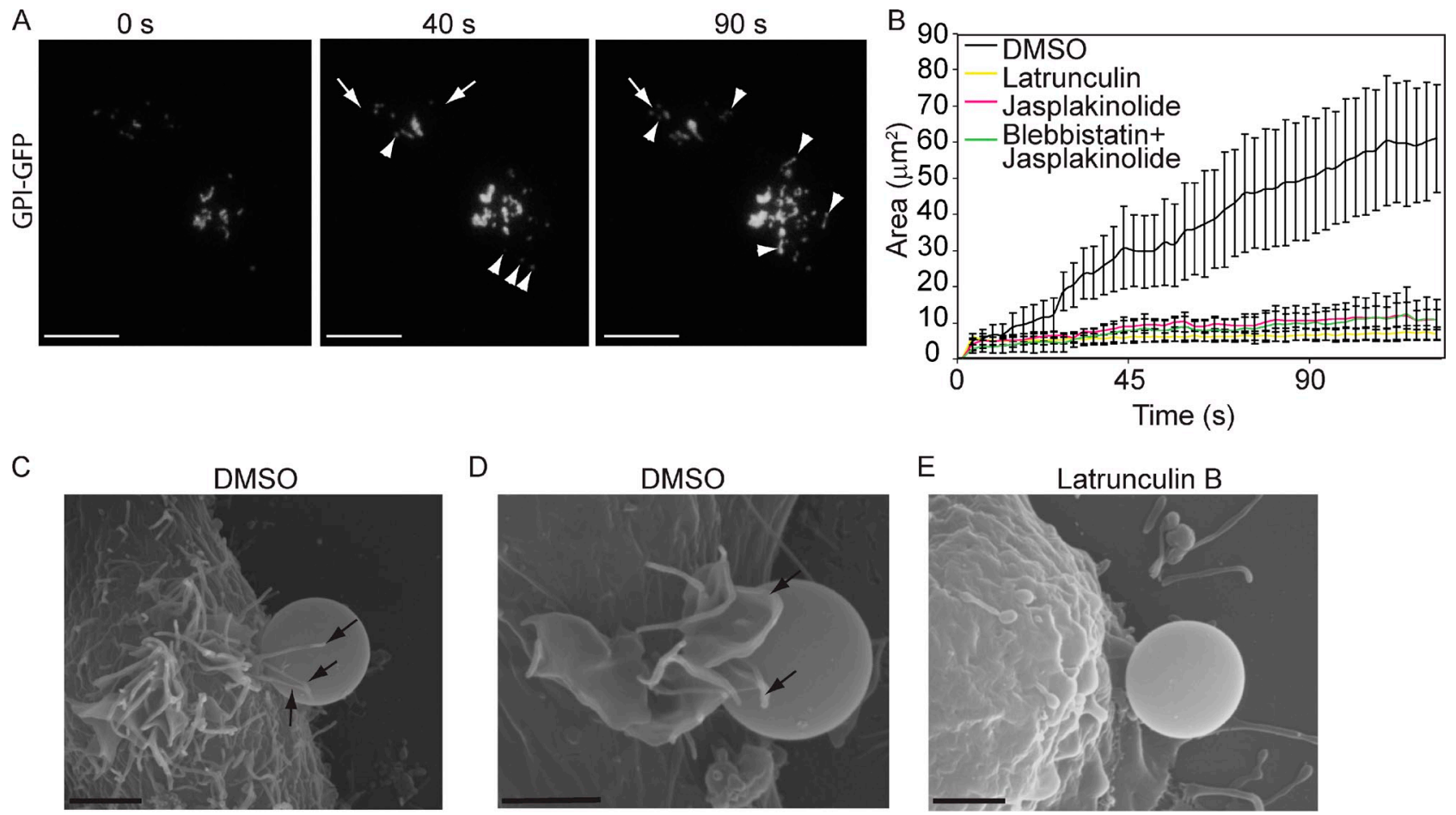

D

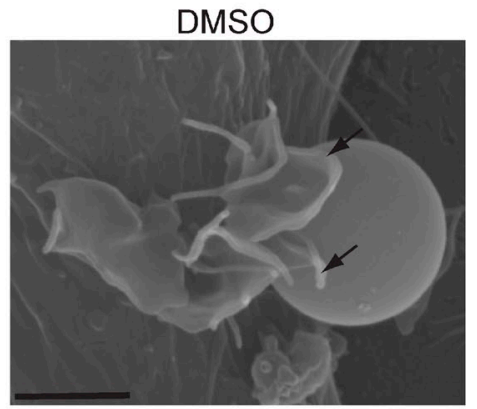

E

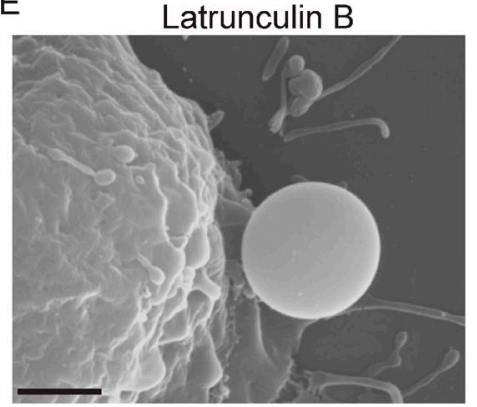

$\mathrm{F}$
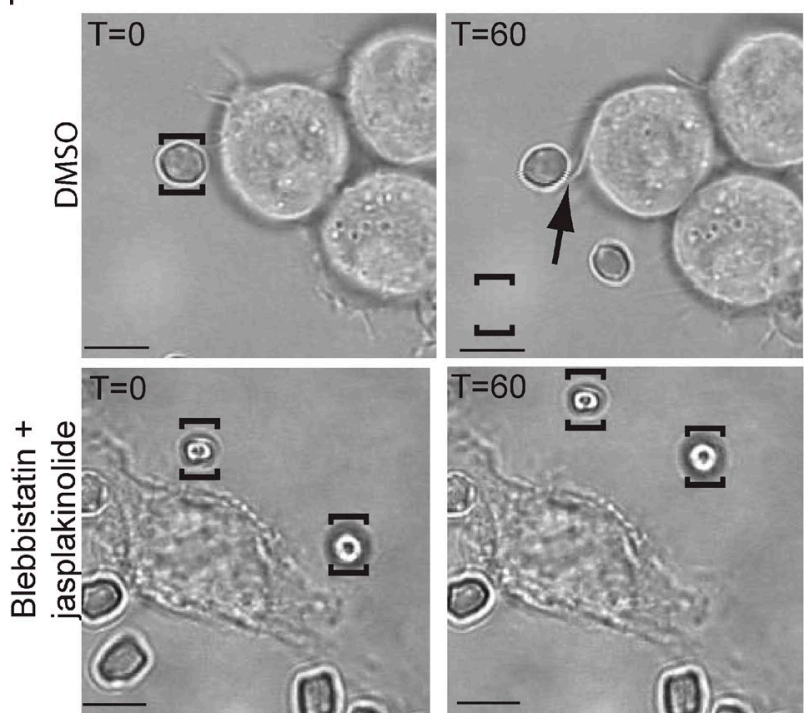

G

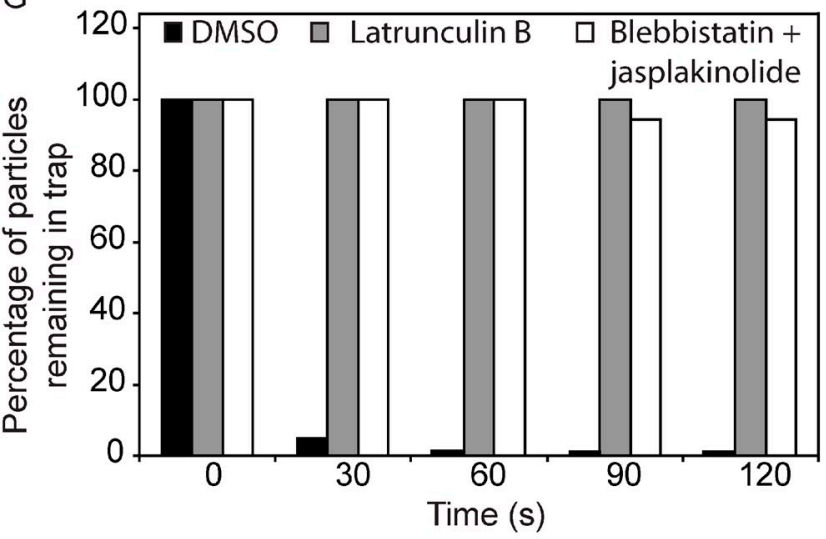

Figure 4. Detection of dynamic macrophage membrane protrusions and their role in binding phagocytic targets. (A and B) Suspended RAW macrophages stably expressing a GPI-linked GFP were treated with actin-perturbing agents or vehicle only (DMSO) and allowed to sediment by gravity onto uncoated glass coverslips, while monitoring fluorescence by TIR-FM. Panel A illustrates the behavior of two control cells shortly after making contact with the coverslip surface. Arrowheads illustrate contact points not present in previous image, arrows point to sites where contacts visible in previous frame were lost; bar, $7 \mu \mathrm{m}$. In $B$, the contact area revealed by TIR-FM in experiments like $A$ is plotted over time for control and drug-treated cells. Data are integrated mean areas \pm SEM obtained by analyzing at least 10 cells from three independent experiments for each condition. (C-E) Scanning electron micrographs of RAW cells exposed briefly $(40 \mathrm{~s})$ to lgG-opsonized latex beads. The presence of membrane protrusions making contact with the phagocytic target is evident in control (C and D) but not in latrunculin-treated (E) cells; bars: $1 \mu \mathrm{m}(C) ; 2 \mu \mathrm{m}(D$ and $E)$. ( $F$ and $G)$ Use of laser tweezers to detect capture of particles placed in the vicinity of macrophages. IgG-opsonized sheep red blood cells (sRBCs) were trapped by an optical tweezer and placed in proximity to control $(T=0$, top) or drug-treated cells $(T=0$, bottom). The position of the optical trap is indicated by the square brackets. After $60 \mathrm{~s}(\mathrm{~T}=60)$ the trap was relocated to a position away from the cell, as indicated by the brackets. Note that the sRBCs are captured by protrusions on the control cells (arrow), displacing them from the trap, but not by the jasplakinolide-treated cells; bar, $8 \mu \mathrm{m}$. (G) Quantitative analysis of target capture measured from optical trap experiments like that in $\mathrm{F}$. The percentage of phagocytic targets that remained in the optical trap is presented as a function of time. Data are means of a total of 30 trapped SRBCs analyzed for each condition tested in three independent experiments.

molecular patterns, such as dectin and mannan receptors (Fig. 5 A; Brown and Gordon, 2001). Hence, dynamic actin rearrangements are required for the capture of diverse targets by multiple receptors in a variety of phagocytic cells.
The GTPase Rac is required for probing and to optimally secure phagocytic targets The mechanism underlying the extension of the actin-driven protrusions that probe for the presence of phagocytic targets 
Figure 5. Dynamic actin is required for the capture of diverse phagocytic targets and is a general requirement for binding by professional phagocytes. (A) Quantitation of the ability of RAW macrophages to bind either C3bi-opsonized sRBCs or unopsonized zymosan after treatment with latrunculin $\mathrm{B}$ or vehicle (DMSO) alone. (B) Effect of actin perturbation on the ability of primary bone marrow-derived macrophages to bind lgG-opsonized phagocytic targets. Primary macrophages were isolated from the bone marrow of $B A L B / C$ mice. A single experiment where 150 macrophages were counted per condition is shown. (C) Effect of latrunculin B on the capture of lgG-coated latex beads by LPS-stimulated bone marrow-derived dendritic cells. Only cells positive for surface expression of $\mathrm{CD} 1 \mathrm{lc}$, as determined by immunofluorescence, were counted. (D) Binding of lgG-opsonized beads to BV2 microglial cells. Where indicated, the cells were treated with PMA (100 $\mathrm{nM}$ for $5 \mathrm{~min}$ ) and/or latrunculin B. A, C, and D show means \pm SEM of three independent experiments.
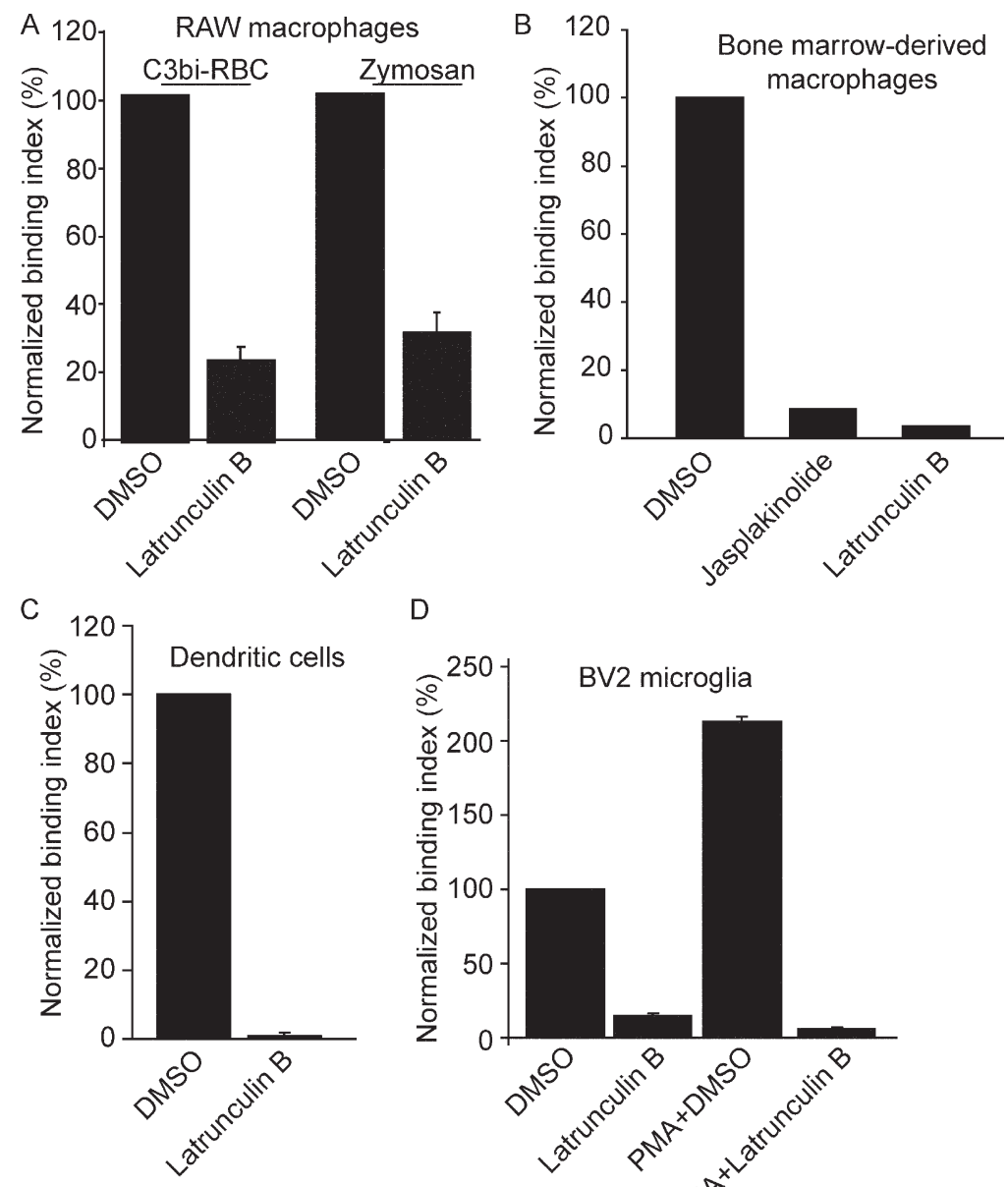

D

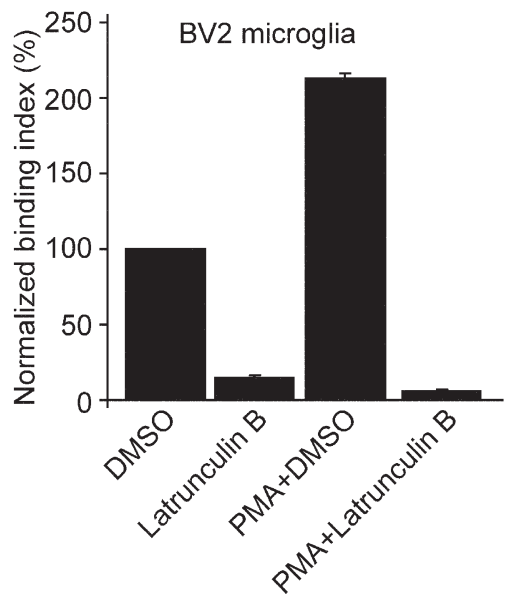

was studied next. The involvement of Rac was investigated using the p21-binding domain (PBD) of PAK, which interacts with the active, GTP-bound form of this GTPase. As shown in Fig. 6 A, constitutive activity of Rac can be detected in unstimulated cells using PAK-PBD. The specificity of the pull-down assay was validated by pretreating the cells with Clostridium difficile toxin B, which glucosylates and inactivates Rho-family GTPases (Just et al., 1994). The toxin eliminated the basal Rac activity (Fig. 6 A) and also the constitutive extension and retraction of protrusions, assessed by TIR-FM of cells transfected with GPI-GFP as above (not depicted). In parallel, toxin B profoundly depressed the ability of the macrophages to bind IgG-opsonized particles (Fig. $6 \mathrm{~B}$ ). Unlike latrunculin B-treated cells, which show few protrusions when analyzed by SEM (Fig. 5 E), cells exposed to toxin B displayed ruffles/ridges (Fig. $6 \mathrm{C}$ ), yet were unable to secure targets on their surface. We believe that this is a consequence of the immobility of these protrusions, as indicated by the TIR-FM experiments.

Because toxin B inactivates not only Rac but also other Rho GTPases, we tested the effects of compound NSC23766, a more selective antagonist of Rac1, to better evaluate the contribution of this GTPase. Under the conditions used, NSC23766 partially inhibited the basal activity of Rac1, as well as particle binding (Fig. 6, A and B). To more definitively establish the role of Rac in particle capture we transfected cells with a dominantnegative allele of this GTPase $(\operatorname{Rac} 1(\mathrm{~T} 17 \mathrm{~N}))$. The inactive mutant was expressed at levels that exceeded the endogenous guanine nucleotide dissociation inhibitor (GDI), as indicated by its association with the plasma membrane (Fig. 6 D). Under these conditions, Rac1(T17N) markedly reduced particle binding to the surface of the transfectants (Fig. 6 E). Expression of a membrane-targeted GFP (PM-GFP) was without effect on binding (Fig. 6, D and E), ruling out nonspecific effects of transfection or of delivery of GFP-tagged proteins to the membrane. Moreover, comparable levels of expression of a dominant-negative form of another GTPase, Cdc42(T17N), were also without effect (Fig. $6 \mathrm{E}$ ), arguing in favor of a specific effect of Rac1.

Macrophages respond to macrophage colony-stimulating factor (MCSF) with Rac activation (Cox et al., 1997; see also Fig. S5 A). Because impairment of Rac diminished particle binding, we anticipated that Rac stimulation would have the opposite effect. Indeed, pretreatment of the macrophages with $10 \mathrm{ng} / \mathrm{ml} \mathrm{MCSF}$ for $6 \mathrm{~min}$ increased the rate of formation of protrusions, as measured by TIR-FM (Video 5) and, more importantly, enhanced the ability of the cells to bind IgG-coated beads by $66.4 \%$ (Fig. S5 B). Together these experiments showed that Rac is critical to the actin-mediated extension of protrusions that trap particles for subsequent phagocytosis.

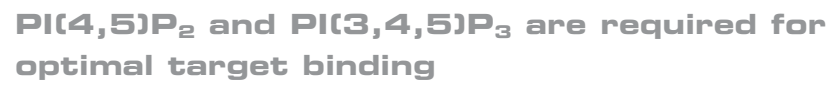

Phosphoinositides are intimately involved in the control of Rho GTPases and actin polymerization. We therefore analyzed their 
A

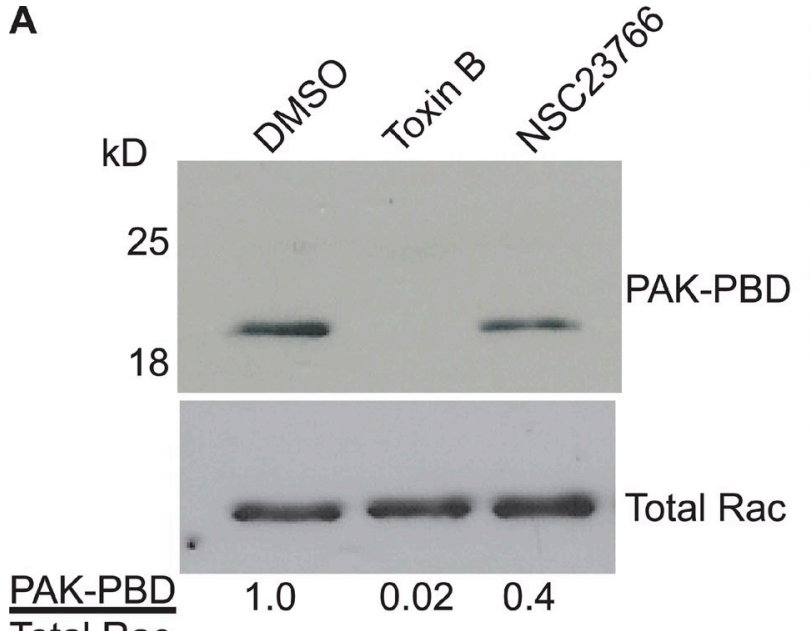

Total Rac

C

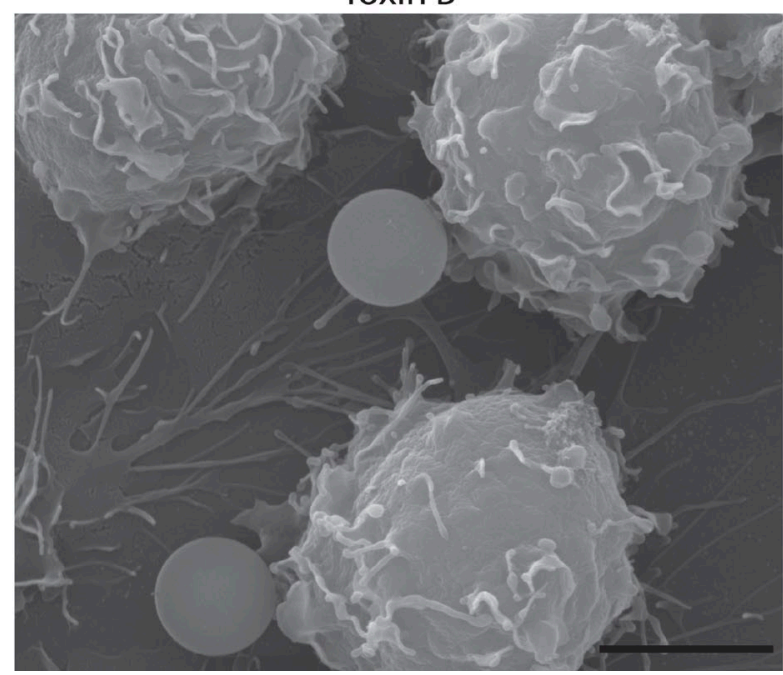

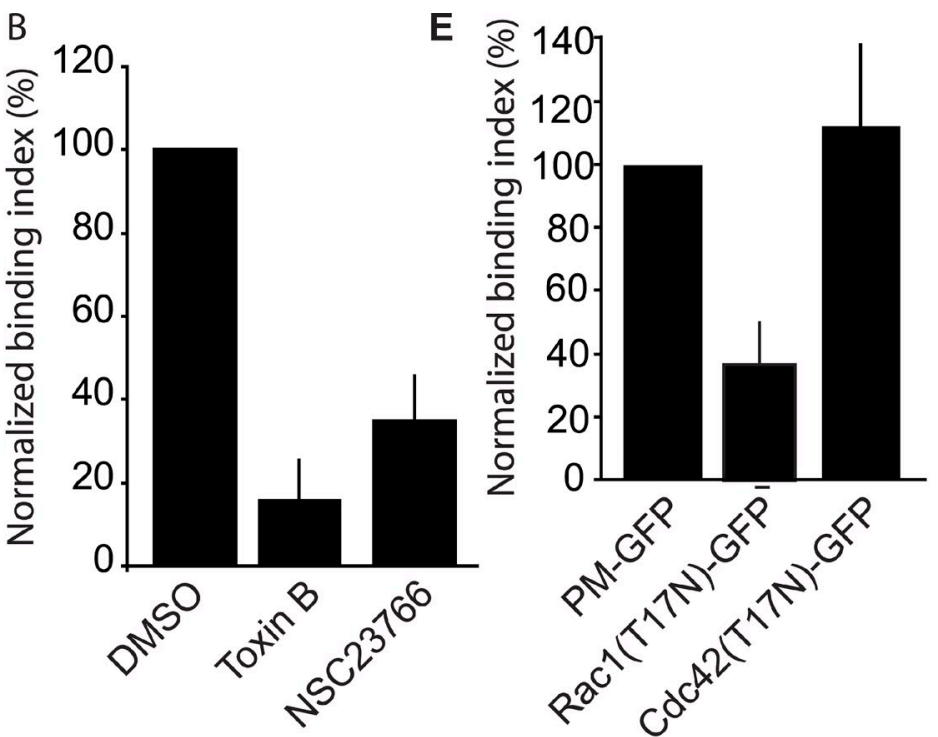

D
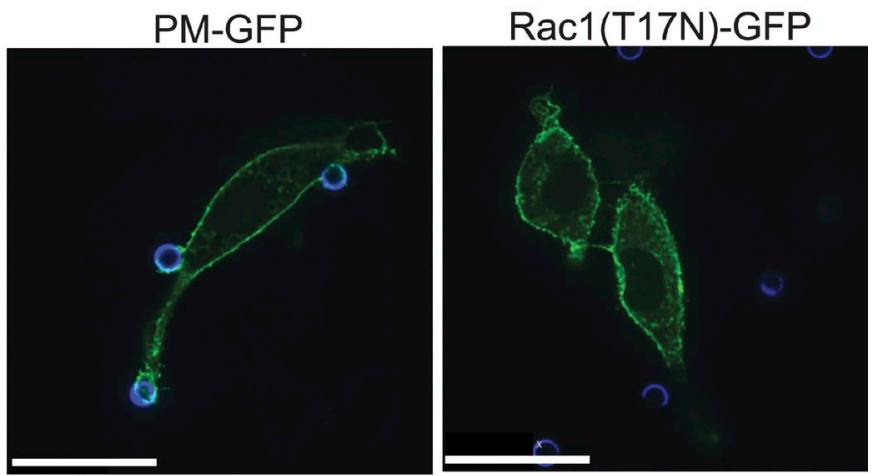

Figure 6. Effect of impaired Rac activation on phagocytic target binding. (A) Detection of active Rac in untreated (DMSO) and in C. difficile toxin B- or NSC23766-treated cells. The presence of Rac-GTP was analyzed by pull-down experiments using PAK-PBD, followed by immunoblotting (top). Total Rac in an aliquot of the lysates was also probed by immunoblotting (bottom). The mean normalized ratio of PAK-PBD-bound Rac/total Rac from two independent experiments is indicated below the blot. (B) Quantitation of the effect of Rac antagonists on binding of lgG-opsonized beads. Data are presented as a binding index normalized to the vehicle control and are means \pm SEM of three experiments, each counting at least 150 macrophages per condition. (C) Scanning electron micrograph of C. difficile toxin B-treated cells incubated with opsonized beads; bar, 5 um. (D) Confocal microscopic images of RAW macrophages transfected with plasmids encoding either Racl (T17N)-GFP or a plasma membrane-targeted GFP (PM-GFP). The transfectants were exposed to lgG-opsonized beads (blue) to assess binding efficiency; bar, $18 \mu \mathrm{m}$. (E) Mean binding index for cells transfected with either Racl (T17N)-GFP, Cdc42(T17N)-GFP, or PM-GFP. Data were normalized to the binding observed in PM-GFP-transfected cells, used as a control, and are means \pm SEM of three experiments each counting at least 60 cells.

possible role in the binding of phagocytic particles. Because prolonged depletion of $\mathrm{PI}(4,5) \mathrm{P}_{2}$ is deleterious to cells, often causing their detachment from the substratum, we used a method to more acutely and precisely control the concentration of the inositide. Cells were transfected with a combination of plasmids that enable the rapid recruitment of type IV phosphoinositide- 5 phosphatase (5-Pase) to the plasmalemma upon addition of rapamycin (van Zeijl et al., 2007). Addition of $1 \mu \mathrm{M}$ rapamycin to such cells induced relocalization of the soluble 5-Pase to the membrane (Fig. $7 \mathrm{~A}$ ) and resulted in vigorous hydrolysis of $\mathrm{PI}(4,5) \mathrm{P}_{2}$, which was verified by monitoring the distribution of PH-PLC $\delta$-GFP, a $\mathrm{PI}(4,5) \mathrm{P}_{2}$-specific probe (not depicted). Importantly, recruitment of the 5-Pase to the membrane drastically reduced the ability of the cells to engage IgG-coated beads (Fig. 7 B), suggesting that $\mathrm{PI}(4,5) \mathrm{P}_{2}$ is required for the process. These observations are congruent with the finding by Mao et al. (2009) that PIP5K $\gamma$ activity is required for macrophages to bind $\mathrm{IgG}$-opsonized targets.

The involvement of $\mathrm{PI}(3,4,5) \mathrm{P}_{3}$, which can stimulate Rac guanine nucleotide exchange factors (Fleming et al., 2000; Côté et al., 2005), was also investigated. To this end RAW macrophages were treated with the phosphatidylinositol 3-kinase (PI3K) inhibitor LY294002. The effectiveness of the inhibitor was validated analyzing cells expressing Akt-PH-RFP, a biosensor for 3-polyphosphoinositides. Although the bulk of the probe is soluble in unstimulated cells, a fraction is detectable in association with the plasma membrane, particularly at sites 
A
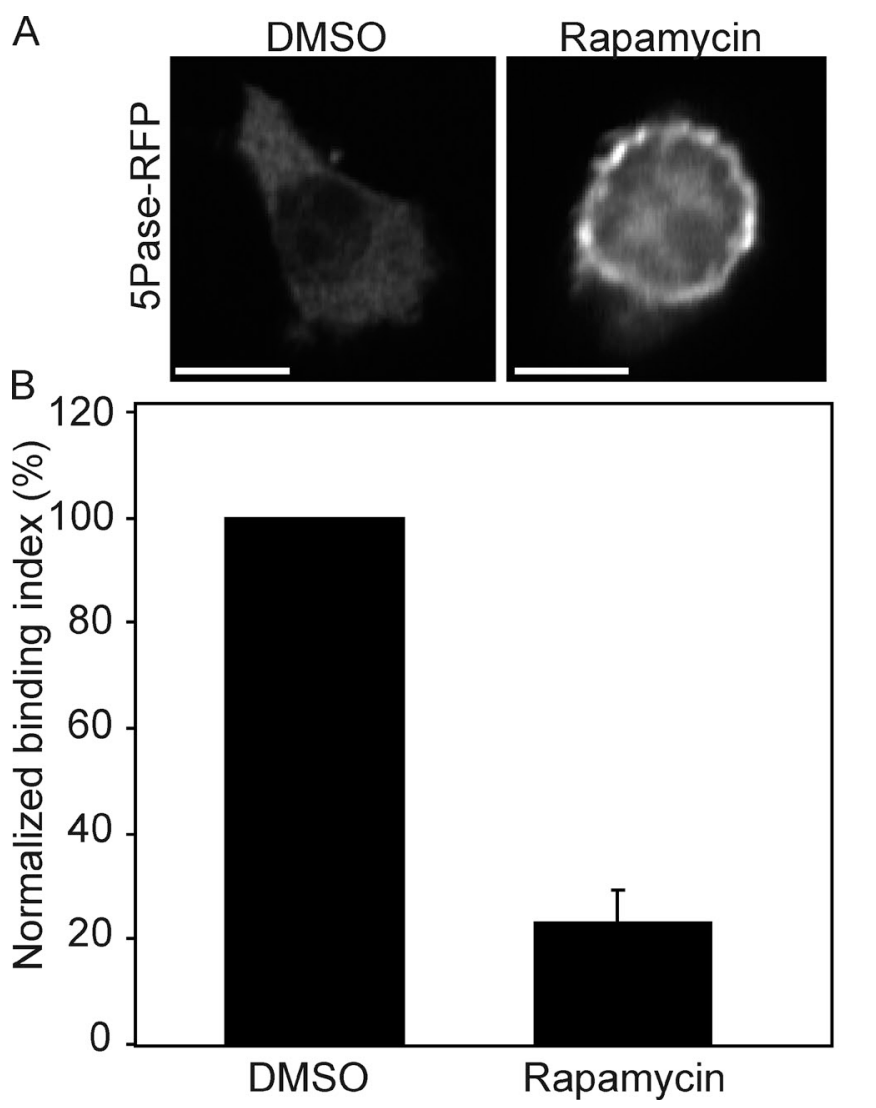

(

C

\section{B}

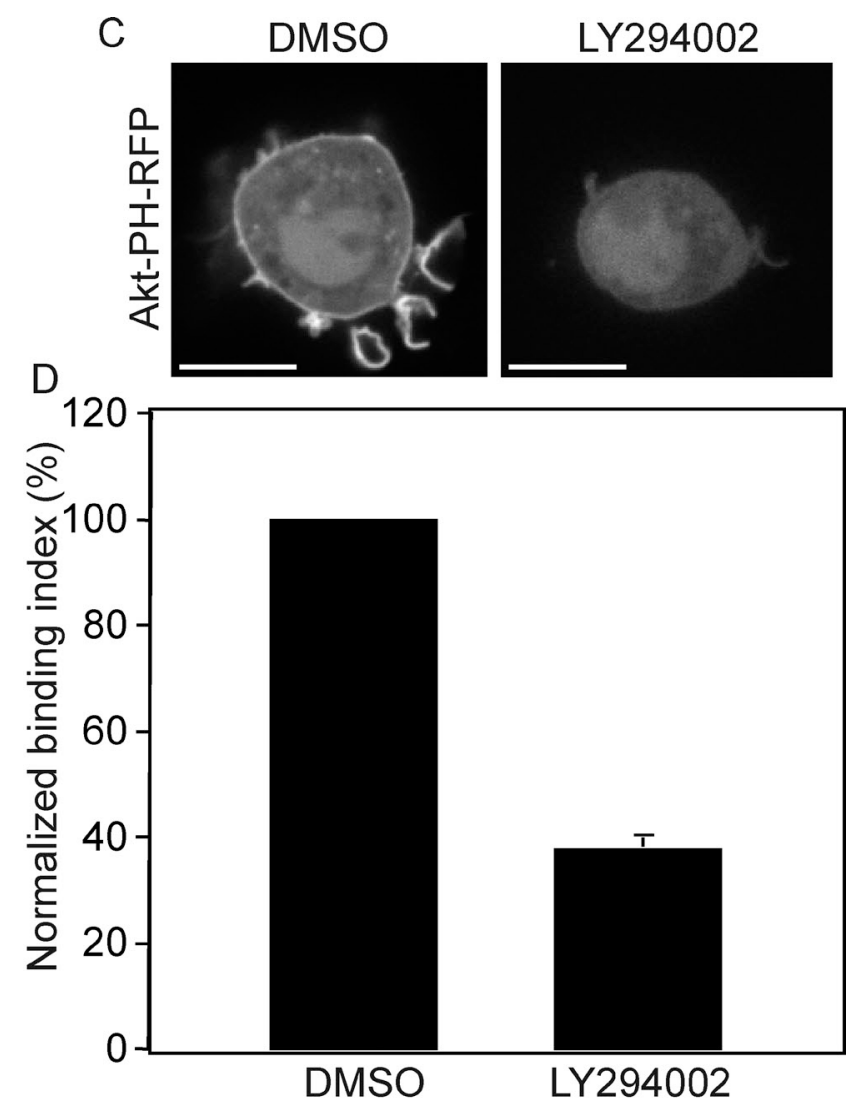

Figure 7. Effect of altered phosphoinositide metabolism on the binding of IgG-opsonized targets. (A) RAW macrophages were transfected with plasmids expressing a form of human type IV phosphoinositide-5 phosphatase (5-Pase) that is RFP tagged and can be targeted to the membrane upon addition of rapamycin (Rap). Shown is the effect of addition of $1 \mu \mathrm{M}$ Rap or vehicle (DMSO) only on the recruitment of the 5-Pase to the membrane. (B) Binding of IgG-opsonized beads to cells transfected with the recruitable 5-Pase after treatment with DMSO or Rap. (C and D) Effect of $100 \mu M$ LY294002 on the distribution of Akt-PH-RFP (C) and on lgG-coated bead binding (D). The images are representative of four independent experiments; bar, $17 \mu \mathrm{m}$. Data in $B$ and $D$ are normalized means \pm SEM of three independent experiments, each counting the beads bound by 150 macrophages.

of active membrane protrusion (Fig. 7 C, left). Addition of LY294002 caused detachment of Akt-PH-RFP from the membrane and largely eliminated the dynamic extension of membrane protrusions (Fig. $7 \mathrm{C}$, right; unpublished data). The drug also reduced the ability of the cells to retain $\mathrm{IgG}$-opsonized latex targets by $62.4 \%$ (Fig. 7 D), indicating $\mathrm{PI}(3,4,5) \mathrm{P}_{3}$ and/or $\mathrm{PI}(3,4) \mathrm{P}_{2}$ contribute to their binding.

\section{Discussion}

Conventional phagocytosis assays have been optimized to yield effective and synchronous engulfment of multiple particles. For this purpose large $(>3 \mu \mathrm{m})$ particles are generally used, which are opsonized densely and overlaid (often sedimented by centrifugation) onto adherent phagocytes. Synchronous uptake is ensured by sudden warming of the medium, after a lengthy preincubation at $0-4{ }^{\circ} \mathrm{C}$. There is general agreement that, under these conditions, firm binding of the targets to the surface of the phagocytes can be obtained whether in the presence of cytochalasin (Newman et al., 1991), after inhibition of Rac (Cox et al., 1997; Caron and Hall, 1998), or in cells treated with tyrosine kinase inhibitors or wortmannin (Greenberg et al., 1993; Ninomiya et al., 1994; Araki et al., 1996). Such observations led to the generally accepted notion that, unlike internalization, binding of phagocytic particles requires neither actin polymerization nor active signaling. Instead, binding is regarded as a passive event, where the engagement of multiple receptors required to provide sufficient avidity to retain the particle results from spontaneous (Brownian) receptor diffusion in the plane of the membrane. According to this model, restricting lateral diffusion of the receptors would reduce the ability of the cells to engage their targets. Indeed, Mao et al. (2009) reported that stabilization of the actin skeleton with jasplakinolide, a maneuver predicted to reduce receptor mobility, impaired particle binding, an observation that we were able to duplicate (Fig. 1 B).

Although the majority of the reports agree with the preceding conclusions, some dissenting observations have been published. Previously, Herskovitz et al. (1977) reported that actin perturbation by cytochalasin treatment of primary human mononuclear cells significantly impaired binding of IgG-sensitized RBC. Sobota et al. (2005) found that optimal particle binding to phagocytes required tyrosine phosphorylation, whereas Dale et al. (2009) not only obtained similar results but also reported that inhibitors of actin polymerization depressed binding. These apparent discrepancies may be attributable to differences in the experimental conditions, particularly the extent of opsonization of the target particle. In this regard, Dale et al. (2009) found that the sensitivity of binding to cytoskeletal disruption was inversely 

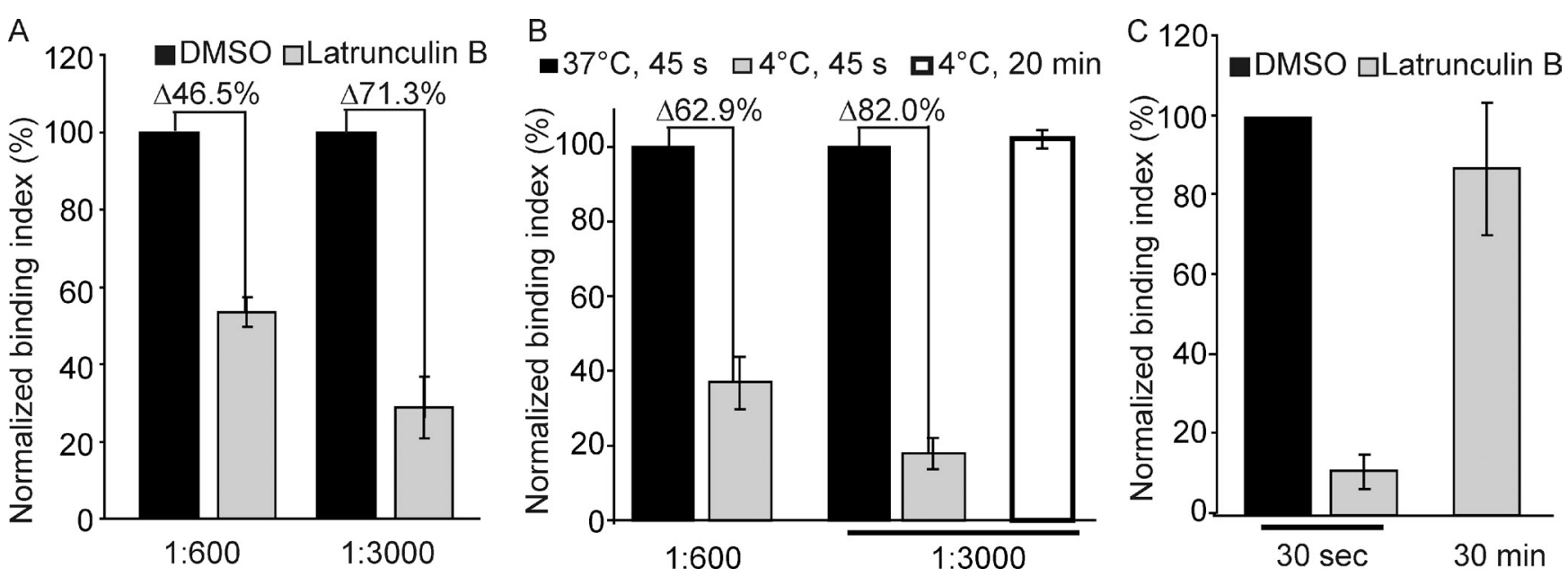

Figure 8. Effect of temperature and opsonin density on particle binding. (A) Effect of opsonin density on binding in the presence and absence of the actin-depolymerizing agent latrunculin $\mathrm{B}$. RAW macrophages were maintained at $37^{\circ} \mathrm{C}$ and treated with either vehicle control (DMSO, black bars) or latrunculin $B(2 \mu M$, gray bars) and then exposed to $s R B C s$ for $3 \mathrm{~min}$. The final dilution of the opsonizing lgG used for each condition is indicated below the abscissa. The percentages above the bars indicate the reduction in binding induced by latrunculin; data are presented as a binding index normalized to DMSO-treated cells. (B) Effect of opsonin density on binding at varying temperatures. RAW macrophages maintained at either $37^{\circ} \mathrm{C}$ or $4^{\circ} \mathrm{C}$ (to inhibit actin rearrangements) were incubated with lgG-opsonized sRBCs for either $40 \mathrm{~s}$ (black and gray bars) or $20 \mathrm{~min}$ (white bar) as indicated. The final dilution of opsonin used for each condition is indicated below the abscissa. The percentages above the bars indicate the reduction in particle binding induced by cooling, relative to control. Data are presented as a binding index normalized to cells maintained at $37^{\circ} \mathrm{C}$. (C) RAW macrophages pretreated with latrunculin B (gray bars) or with vehicle only (DMSO; black bar) were exposed to lgG-opsonized beads for either $30 \mathrm{~s}$ or 30 min, as indicated, before washing. Data are means \pm SEM of three independent experiments.

proportional to opsonin density, an important observation that we have replicated (Fig. 8, A and B). Additionally, we found that the duration of the coincubation of cells and particles and the stringency of the subsequent washing procedure also dictate the effect of the inhibitors (Fig. 8, B and C). As mentioned, most studies investigating phagocytosis have used lengthy incubations in the cold, often in combination with centrifugation of phagocytic targets onto the cells as a means of synchronizing particle engulfment. Presumably, these experimental conditions circumvented the necessity of dynamic cytoskeletal changes that would otherwise be required for target capture. Indeed, incubation of cells at $4^{\circ} \mathrm{C}$ alone, which inhibits actin dynamics, is sufficient to impair particle binding very significantly when short incubations with targets are used (Fig. 8 B). Importantly, this impairment can be completely circumvented by mimicking the lengthy incubations commonly used in other studies, explaining why particle capture was incorrectly deemed as a passive event (Fig. 8, B and C).

The lower opsonin densities and short incubations at $37^{\circ} \mathrm{C}$ used in our studies are much more likely to mimic the physiological situation, where neither the particles nor the phagocytes are stationary. Indeed, small pathogens are anticipated to make very transient contacts with phagocytes, driven away from the surface by thermal or hydrodynamic forces, or propelled by ciliary or flagellar motion. In such cases, an effective capture mechanism is required and passive lateral diffusion of receptors is unlikely to suffice. Our findings indicate that phagocytes improve the effectiveness of the binding process by actively probing their environment with actin-driven protrusions. Attachment of macrophages to target particles by means of thin extensions had been reported (Kress et al., 2007), but neither the underlying mechanism nor its relevance to particle binding were explored.
We found that the extensions are driven at least in part by Rac and require both $\mathrm{PI}(4,5) \mathrm{P}_{2}$ and $\mathrm{PI}(3,4,5) \mathrm{P}_{3}$. Of note, the extensions are formed continuously in synthetic media ostensibly devoid of cytokines, growth factors, or other soluble agonists. Interaction of integrins with the substratum is also unlikely to be responsible for the spontaneous formation of extensions, which were observed by TIR-FM in cells settling onto BSA-coated glass. This intrinsic ability of macrophages to probe the environment for particulate targets is akin to the continuous sampling of the fluid milieu that dendritic cells perform in search for antigenic material. It thus appears that a subset of the Rho-family GTPases is constitutively activated in myeloid cells, to support their role in environmental surveillance.

In summary, we conclude that two distinct stages of the phagocytic process require actin polymerization dependent on Rho-family GTPases and phosphoinositides: the initial capture of the prey and its subsequent internalization. The requirement for actin-mediated probing is greatest when sparsely opsonized and/or rapidly moving particles are the target, but is obviated when heavily opsonized particles are exposed to the phagocyte surface for extended periods, enabling passive engagement of ligands by receptors. By contrast, the need of the engulfment process for actin remodelling is absolute.

\section{Materials and methods}

\section{Reagents}

Rat anti-mouse Fcyll/III antibody (clone 2.4G2) was purchased from the Sunnybrook Health Sciences Centre Hybridoma core facility. Rat antimouse FcyRI (clone 290322) and rat isotype control antibodies lgG2a and lgG2b were obtained from R\&D Systems. The hamster anti-mouse Cd1 lc antibody (clone N418) was from eBioscience. All secondary antibodies were from Jackson ImmunoResearch Laboratories, Inc. Streptavidin 655Quantum dots were from Invitrogen. Jasplakinolide and LY294002 were 
purchased from Enzo Life Sciences, Inc. and EMD, respectively. Blebbistatin, latrunculin B, and other reagents were purchased from SigmaAldrich. All tissue culture supplies were from Wisent, Inc.

\section{Tissue culture and transient transfection}

RAW264.7 murine macrophages obtained from the American Type Culture Collection were maintained in DME or RPMI 1640 with $5 \%$ (vol/vol) fetal bovine serum at $37^{\circ} \mathrm{C}$ in a $5 \% \mathrm{CO}_{2}$ incubator. For live-cell imaging or incubations in the absence of $\mathrm{CO}_{2}$, Hepes-buffered RPMI (HPMI) medium was used. BV2 microglial cells, a gift from T. Trang (The Hospital for Sick Children, Toronto, Ontario, Canada) were similarly maintained. Primary bone marrow-derived dendritic cells were isolated from 13-wk-old C57B6 mice and cultured in RPMl supplemented with $10 \%$ FCS and $10 \mathrm{ng} / \mathrm{ml}$ GM-CSF for 8 to $12 \mathrm{~d}$. Dendritic cells were identified by CD 1 lc immunoreactivity.

Transfections were performed using FuGene HD (Roche) transfection reagent according to the manufacturer's protocol. Routinely a total of 2-4 $\mathrm{pg}$ of plasmid DNA with $5 \mu \mathrm{l}$ of transfection reagent was added to each well of a 12-well tissue culture plate and incubated 18-24 $\mathrm{h}$ before use. The plasmids used in this study were GPI-GFP (Nichols et al., 2001), PM-GFP (Tervel et al., 1999), Rac(T17N)-GFP and Cdc42(T17N)-GFP (generous gifts from the late Dr. Gary Bokoch, Scripps Research Institute, La Jolla, CA), PH-PLC8-GFP (Várnai and Balla, 1998), Akt-PH-RFP (cloned as described [Haugh et al., 2000] and fused to RFP), and PM-FRB-CFP and FKB12-RFP-5pase (van Zeiil et al., 2007).

\section{Pharmacological treatments}

Jasplakinolide, blebbistatin, and latrunculin $\mathrm{B}$ were used at a final concentration of 1,60 , and $2 \mu M$ or $4 \mu M$, respectively. The drugs were added for the indicated period before and also during the experimental measurement. Blebbistatin was added $20 \mathrm{~min}$ before the addition of jasplakinolide. Treatment with Clostridium difficile toxin B was for $3-4$ h at $50 \mathrm{ng} / \mathrm{ml}$. NSC23766 treatment was at $500 \mathrm{\mu g} / \mathrm{ml}$ for 18-24 h before experimentation. LY294002 was used at $100 \mu \mathrm{M}$. Dendritic cells were treated overnight with $50 \mathrm{ng} / \mathrm{ml}$ lipopolysaccharide (Sigma-Aldrich) to promote adherence to glass and phagocytic activity.

\section{Binding and phagocytosis assays}

Latex beads (3.87- $\mu \mathrm{m}$ diameter; Bangs Laboratories, Inc.) were opsonized with human $\lg G(3 \mathrm{mg} / \mathrm{ml})$ for at least $1 \mathrm{~h}$. Sheep red blood cells (sRBCs) were opsonized with rabbit anti-sheep lgG by mixing sRBCs with different dilutions of opsonin in PBS at room temperature as described previously (Vieira et al., 2001). Alternatively, sRBCs were opsonized with C3bi as described previously (Jongstra-Bilen et al., 2003), and were added to serum-starved cells pretreated with $100 \mathrm{nM}$ phorbol 12-myristate 13-acetate (PMA) to activate CR3 receptors. In brief, sRBCs were opsonized with subagglutinating concentrations of rabbit anti-sheep $\lg M$ in PBS supplemented with $0.5 \mathrm{mM} \mathrm{MgCl} 2$ and $0.5 \mathrm{mM} \mathrm{CaCl}\left(\mathrm{PBS}^{2+}\right)$ for $1 \mathrm{~h}$ at room temperature. After washing twice with $\mathrm{PBS}^{2+}$, sRBCs were incubated with C5-deficient serum (Sigma-Aldrich) for $20 \mathrm{~min}$ at $37^{\circ} \mathrm{C}$ with constant mixing to opsonize with C3bi. Opsonized sRBCs were subsequently washed with $\mathrm{PBS}^{2+}$ and used immediately. Unopsonized Alexa 455-labeled zymosan, a gift from Dr. G.D. Fairn (The Hospital for Sick Children, Toronto, Ontario, Canada), was used at a final concentration of $20 \mathrm{\mu g} / \mathrm{ml}$. For binding experiments, phagocytic targets were added to individual wells of a 12-well tissue culture plate, centrifuged for $15 \mathrm{~s}$ at $277 \mathrm{~g}$, and then incubated at $37^{\circ} \mathrm{C}$ for $35 \mathrm{~s}$ before 5 vigorous washes with ice-cold PBS. Cells were then fixed with $4 \%$ (vol/vol) paraformaldehyde or ice-cold methanol, as appropriate. To calculate the binding index (i.e., the number of bound beads/number of cells), at least 150 macrophages were counted per condition. To facilitate comparison, the experimental data were normalized to the binding index of the control within each experiment, which was designated as $100 \%$.

Aggregated lgG (aglgG) was generated and used as described previously (Mero et al., 2006), except that incubation with the cells was at $15^{\circ} \mathrm{C}$ and quantification of binding was performed by flow cytometry.

\section{Flow cytometry}

While adherent, macrophages were labeled with anti-FcyRII/III (clone $2.4 \mathrm{G} 2$ ) or an irrelevant isotype (lgG2b)-matched control at $10 \mathrm{\mu g} / \mathrm{ml}$. Bound primary antibody was detected using DyLight 488-conjugated donkey anti-rat secondary antibody. For the detection of Fc $\gamma R \mathrm{Rl}$, rat anti-mouse FcyRI (clone 290322) or isotype (lgG2a)-matched control antibodies were used at $5 \mathrm{\mu g} / \mathrm{ml}$. Receptor expression was quantified using a FACScalibur (Becton Dickinson) flow cytometer and background fluorescence was corrected using blebbistatin-treated RAW cells alone. In some experiments primary antibody was substituted for soluble aggregated lgG that was subsequently labeled with DyLight 488-conjugated goat anti-human secondary antibodies.

\section{Bright-field and fluorescence microscopy}

Differential interference contrast (DIC) images were acquired using a microscope (DMIRE2; Leica) ouffitted with $63 x$ or $100 x$ oil immersion objectives. Fluorescence images were acquired using spinning-disk confocal microscopy. The spinning-disk confocal systems (Quorum Technologies) used in our laboratory are based on an Axiovert 200M microscope (Carl Zeiss, Inc.) with $63 \times$ (NA 1.4) or 100x (NA 1.45) oil immersion objectives, equipped with diode-pumped solid-state lasers $(440,491,561,638$, and $655 \mathrm{~nm}$; Spectral Applied Research) and a motorized XY stage (Applied Scientific Instrumentation). Images were acquired using back-thinned, electron-multiplied (model C9100-13 ImagEM; Hamamatsu Photonics) or conventional cooled charge-coupled device (model C4742-95-12ER; Hamamatsu Photonics) cameras controlled by Volocity software 4.1.1 (PerkinElmer).

\section{Fab fragment preparation}

To digest anti-FcyR antibodies, immobilized papain (Thermo Fisher Scientific) was used as described in the manufacturer's protocol. Fab fragments were purified by FPLC using a Sephacryl S100 column. Fab-enriched fractions free of $\mathrm{Fc}$ fragments were isolated after identification by nonreducing SDS-PAGE and Western blot analysis.

\section{Receptor labeling, single-particle tracking, and diffusion analysis}

RAW cells cultured on a coverslip were blocked for $5 \mathrm{~min}$ in blocking medium (HPMl, $5 \%$ [vol/vol] goat serum). To label FcyRll/III, primary Fab fragments derived from clone $2.4 \mathrm{G} 2$ were diluted in blocking medium and incubated with cells for $10 \mathrm{~min}$. Next, a biotinylated secondary Fab fragment diluted to $0.75 \mathrm{\mu g} / \mathrm{ml}$ was added for $8 \mathrm{~min}$. The above steps were performed with medium warmed to $37^{\circ} \mathrm{C}$. After washing with cold PBS, streptavidin-conjugated $655-\mathrm{Qdots}$ diluted in PBS with $5 \%$ (vol/vol) goat serum were added for $5 \mathrm{~min}$ at $4^{\circ} \mathrm{C}$. The coverslip was then washed with ice-cold HPMl containing $0.2 \mathrm{\mu g} / \mathrm{ml}$ biotin, to block any unengaged streptavidin. Coverslips were then transferred to a Leiden chamber with warm $\mathrm{HPMl}$ and the chamber placed on a heated stage on a microscope (Axiovert 200M; Carl Zeiss, Inc.) equipped with a custom 2.5x lens and a 100x (NA 1.45) objective. Movies of individual cells were acquired using Volocity software at a frame rate of $33.3 \mathrm{~Hz}$ by epifluorescence microscopy. The imaged receptors were detected and tracked as described in Jaqaman et al. (2008). In brief, particle positions and intensities-which were sub-resolution features - were estimated by (i) detecting significant local intensity maxima and (ii) fitting Gaussian kernels approximating the twodimensional point spread function of the microscope.

Receptor diffusion types were extracted using a moment scaling spectrum (MSS) analysis of receptor displacements (Ferrari et al., 2001; Ewers et al., 2005): (i) For each time shift $\tau$, the Oth to 6th displacement moments, $\mu_{0}(\tau)$ to $\mu_{6}(\tau)$, were calculated (note that the commonly used mean square displacement [MSD] is the second moment). (ii) From the relationship

$$
\mu_{m}(\tau)=4 D_{m} \tau^{\alpha_{m}}
$$

for $m=0 \ldots 6$, describing how each moment scaled with time shift $\tau$, the generalized diffusion coefficient $D_{m}$ and power $\alpha_{m}$ were estimated. In the commonly used MSD analysis, the power $\alpha_{2}=1$ for unconfined diffusion. The second moment yielded the "normal" diffusion coefficient $D_{2}$. (iii) The plot of $\alpha_{m}$ versus $m$ is called the moment scaling spectrum. For a strongly self-similar process, it follows a straight line, the slope of which indicates the type of motion underlying the analyzed trajectory: a slope of 0.5 implies normal diffusion, a slope $<0.5$ indicates confined diffusion, and a slope $>0.5$ indicates super-diffusion.

Because of the finite length of receptor trajectories, however, 0.5 could not be used as the cut-off between the different motion types. Instead, trajectory length-dependent confined diffusion and super-diffusion cut-offs were calculated to ensure $95 \%$ confidence in the classification. To determine the cut-offs as functions of trajectory length, 1,000 2D-simulated Brownian trajectories at every length (20-500 frames) were subjected to the MSS analysis, yielding a distribution of MSS line slopes for every length. The length-dependent confined diffusion cut-offs were then taken as the 2.5th percentile of the distributions, whereas the super-diffusion cut-offs were taken as the 97.5th percentile. Trajectories shorter than 20 frames were too short to analyze and classify, whereas for trajectories longer than 500 frames the cut-offs were approximated by the cut-off value at 500 frames. These thresholds were independent of the Brownian motion diffusion 
coefficient, as verified by performing two separate simulations with different diffusion coefficients ( 1 and 0.1 pixels $^{2} /$ unit time).

The confinement radius of receptors undergoing confined diffusion was derived from the scatter of positions along each trajectory. In particular, an eigenvalue decomposition of the variance-covariance matrix of the positions was performed, from which the positional standard deviation was calculated as

$$
\sqrt{\left(\lambda_{2}+\lambda_{2} / 2\right)}
$$

( $\lambda_{1}$ and $\lambda_{2}$ are the two eigenvalues). Assuming that receptor motion inside the confinement area was a random walk, in which case a receptor would visit every position inside its confinement region with uniform probability (Dorn et al., 2005), the confinement radius $R$ was then calculated as

$$
R=2 x \sqrt{\lambda_{2}+\lambda_{2} / 2}
$$

The detected particles were tracked using a 2-step single-particle tracking algorithm that could follow dense receptor fields and generate complete trajectories by closing gaps and capturing merging and splitting events. In the first step, the algorithm linked particles between consecutive frames, seeking a robust, spatially global solution. However, the tracks generated in the first step started and ended not only because of true particle appearance and disappearance, but also because of temporary particle disappearance, e.g., due to Q-dot blinking. Thus, in the second step, the algorithm generated complete particle trajectories by linking the ends and starts of the track segments from the first step to close gaps resulting from temporary particle disappearance. In this step, all track segments were allowed to compete with each other, resulting in a spatially and temporally global solution, adding stability to the tracker under high receptor density conditions. The cost functions used to weigh competing particle and track segment assignments were based on distance and intensity. All movies were analyzed using the same tracking parameters.

\section{Microelastic mapping by atomic force microscopy}

All force measurements were obtained using a Bioscope scanning-probe system (Digital Instruments) equipped with an extended range "J" scanner. This system was integrated with a confocal microscope (Fluoview 500; Olympus) and was controlled by a Nanoscope IIIA controller (Digital Instruments) using version $4.49 \mathrm{r} 3$ of the software. Cells were probed with $200-\mu \mathrm{m}$ triangular silicon nitride cantilevers (Veeco) with an approximate spring constant of $0.06 \mathrm{~N} / \mathrm{m}$

Force curve data were acquired by making single measurements at multiple sites on individual cells, as defined by the experimenter. All measurements were made in contact mode AFM with a scan rate of $1 \mathrm{~Hz}$ and a relative deflection set point of $20 \mathrm{~nm}$. Reference force curve data points were acquired by making measurements against glass tissue culture dishes. At least four cells per condition per experiment were tested. Analysis of force curve data was performed using SPMCON-Nanoscope force curve analysis software.

\section{Total internal reflection fluorescence microscopy (TIR-FM)}

RAW macrophages stably expressing a GPI-linked GFP were scraped into $1 \mathrm{ml}$ of HPMl and incubated for $10 \mathrm{~min}$ at $37^{\circ} \mathrm{C}$. Coverslips used in these experiments had previously been incubated in a solution of $1 \%$ (wt/vol) BSA for $1 \mathrm{~h}$ and washed. Individual coverslips were placed in a Leiden chamber with warm HPMI and then placed in a microscope stage heater set to $37^{\circ} \mathrm{C}$. Cells were added and contact of the plasma membrane with the coverslip was imaged by TIR-FM microscopy using an inverted fluorescence microscope (Axiovert 200M; Carl Zeiss, Inc.) ouffitted with a TIR-FM slider, a 100x objective (NA 1.4), a 488 diode-pumped solid-state laser (Spectral Applied Research), and a back-thinned, electron multiplied and cooled charged-coupled device camera (Hamamatsu Photonics). ImageJ software (National Institutes of Health, Bethesda, MD) was used to determine the surface area of the contact zones.

\section{Scanning electron microscopy (SEM)}

RAW macrophages were cultured on 18-mm coverslips and beads were allowed to bind to them as described above, except that washing was performed gently using PBS at room temperature, to image also loosely bound beads in drug-treated cells. Next, the cells were fixed with $2 \%$ (vol/vol) glutaraldehyde and processed for SEM using standard methods.
Active Rac determinations

GTP-bound Rac was isolated using GST-PAK-PBD bound to glutathionederivatized beads, as described previously (Di Ciano et al., 2002). In brief, bacteria expressing recombinant GST-PAK-PBD were lysed in STE buffer $(10 \mathrm{mM}$ Tris, $150 \mathrm{mM} \mathrm{NaCl}$, and $1 \mathrm{mM}$ EDTA, pH 8.0) using a French Press. After centrifugation the supernatant was collected, Triton X-100 was added (1\% [vol/vol] final concentration), and this mixture was incubated with glutathione-Sepharose beads (GE Healthcare) to bind GST-PAK-PBD. To pull down active Rac, cells were lysed in MLB buffer $(25 \mathrm{mM}$ Hepes, $150 \mathrm{mM} \mathrm{NaCl}, 1 \%$ [vol/vol] lgepal, $10 \mathrm{mM} \mathrm{MgCl}, 1 \mathrm{mM} \mathrm{EDTA}$, and $10 \%$ [vol/vol] glycerol, $\mathrm{pH} \mathrm{7.5)} \mathrm{containing} \mathrm{protease} \mathrm{inhibitors} \mathrm{and} \mathrm{the} \mathrm{cell}$ lysates were incubated with PAK-PBD-bound beads at $4^{\circ} \mathrm{C}$ for $1 \mathrm{~h}$ with mixing. Total levels of Rac (determined from whole-cell lysates) and GTPbound Rac (determined from bead slurries) were analyzed by immunoblot using the anti-Rac monoclonal antibody 23A8 (Millipore).

\section{Use of laser tweezers to monitor particle binding}

Sheep red blood cells (sRBCs) were opsonized as described previously (Vieira et al., 2001) and added to coverslips with adherent RAW cells. Individual SRBCs, which were more easily trapped than latex beads, were captured in an optical trap using a laser tweezer system (3W Nd:Yag infrared laser; Molecular Machines \& Industries) installed on a microscope (Axiovert 200M; Carl Zeiss, Inc.) with a 100x objective (NA 1.4). Trapped sRBCs were held by the laser tweezer in the vicinity $(\sim 1 \mu \mathrm{m})$ of the cell surface and the ability of the cell to capture the phagocytic target with a force exceeding that of the optical trap was measured over time.

\section{Statistical analyses}

Statistical parameters were determined using Prism 5 software (GraphPad Software, Inc.). Significance of differences was calculated using paired $t$ tests.

\section{Online supplemental material}

Fig. S1 shows the specificity of the purified 2.4G2 Fab fragment and its ability to label monomeric FcyRll/III. Fig. S2 shows the effect of actin depolymerization on surface expression of FcyR. Fig. S3 shows SPT analysis of the effect of actin depolymerization on the mobility of FcyR. Fig. S4 shows the localization of FcyRII/III to membrane ruffles and filopodia. Fig. S5 illustrates the effect of MCSF on actin and particle binding. Video 1 shows the dynamic behavior of RAW macrophages. Video 2 shows the constitutive probing behavior of RAW macrophages expressing a GPI-GFP. Video 3 demonstrates the effects of latrunculin B on the probing behavior of RAW macrophages expressing GPI-GFP. Video 4 shows the rapid onset of frustrated phagocytosis as a GPI-GFP-expressing RAW macrophage contacts an lgGopsonized coverslip. Video 5 demonstrates the effect of MCSF on the probing behavior of GPI-GFP-expressing RAW cells.

The authors are grateful to D. Ng and W.K. Glowacka for the generous gift of purified bone marrow-derived dendritic cells.

This work was supported by Canadian Institutes of Health Research (CIHR) grant 7075 awarded to S. Grinstein. AFM equipment was supported by $\mathrm{CHHR}$ Research Resource grant PRG-80174 to C.M. Yip. K. Jaqaman was supported by $\mathrm{NIH}$ grants P5O GM068762 and UO 1 GM067230. R.S. Flannagan is the recipient of a ClHR fellowship and S. Grinstein is the current holder of the Pitblado Chair in Cell Biology.

Submitted: 12 July 2010

Accepted: 11 November 2010

\section{References}

Araki, N., M.T. Johnson, and J.A. Swanson. 1996. A role for phosphoinositide 3-kinase in the completion of macropinocytosis and phagocytosis by macrophages. J. Cell Biol. 135:1249-1260. doi:10.1083/jcb.135.5.1249

Botelho, R.J., M. Teruel, R. Dierckman, R. Anderson, A. Wells, J.D. York, T. Meyer, and S. Grinstein. 2000. Localized biphasic changes in phosphatidylinositol4,5-bisphosphate at sites of phagocytosis. J. Cell Biol. 151:1353-1368. doi:10.1083/jcb.151.7.1353

Brown, G.D., and S. Gordon. 2001. Immune recognition. A new receptor for betaglucans. Nature. 413:36-37. doi:10.1038/35092620

Caron, E., and A. Hall. 1998. Identification of two distinct mechanisms of phagocytosis controlled by different Rho GTPases. Science. 282:1717-1721. doi:10.1126/science.282.5394.1717

Côté, J.F., A.B. Motoyama, J.A. Bush, and K. Vuori. 2005. A novel and evolutionarily conserved PtdIns(3,4,5)P3-binding domain is necessary for DOCK180 signalling. Nat. Cell Biol. 7:797-807. doi:10.1038/ncb1280 
Cox, D., P. Chang, Q. Zhang, P.G. Reddy, G.M. Bokoch, and S. Greenberg. 1997. Requirements for both Rac1 and $\mathrm{Cdc} 42$ in membrane ruffling and phagocytosis in leukocytes. J. Exp. Med. 186:1487-1494. doi:10.1084/jem.186.9.1487

Dale, B.M., D. Traum, H. Erdjument-Bromage, P. Tempst, and S. Greenberg. 2009. Phagocytosis in macrophages lacking $\mathrm{Cbl}$ reveals an unsuspected role for $\mathrm{Fc}$ gamma receptor signaling and actin assembly in target binding. J. Immunol. 182:5654-5662. doi:10.4049/jimmunol.0803942

Di Ciano, C., Z. Nie, K. Szászi, A. Lewis, T. Uruno, X. Zhan, O.D. Rotstein, A. Mak, and A. Kapus. 2002. Osmotic stress-induced remodeling of the cortical cytoskeleton. Am. J. Physiol. Cell Physiol. 283:C850-C865.

Dorn, J.F., K. Jaqaman, D.R. Rines, G.S. Jelson, P.K. Sorger, and G. Danuser. 2005. Yeast kinetochore microtubule dynamics analyzed by highresolution three-dimensional microscopy. Biophys. J. 89:2835-2854. doi:10.1529/biophysj.104.058461

Ewers, H., A.E. Smith, I.F. Sbalzarini, H. Lilie, P. Koumoutsakos, and A. Helenius. 2005. Single-particle tracking of murine polyoma virus-like particles on live cells and artificial membranes. Proc. Natl. Acad. Sci. USA. 102:1511015115. doi:10.1073/pnas.0504407102

Ferrari, R., A.J. Manfroi, and W.R. Young. 2001. Strongly and weakly self-similar diffusion. Physica D. 154:111-137. doi:10.1016/S0167-2789(01)00234-2

Flannagan, R.S., G. Cosío, and S. Grinstein. 2009. Antimicrobial mechanisms of phagocytes and bacterial evasion strategies. Nat. Rev. Microbiol. 7:355-366. doi:10.1038/nrmicro2128

Fleming, I.N., A. Gray, and C.P. Downes. 2000. Regulation of the Rac1-specific exchange factor Tiam1 involves both phosphoinositide 3-kinase-dependent and -independent components. Biochem. J. 351:173-182. doi:10.1042/ 0264-6021:3510173

Frick, M., K. Schmidt, and B.J. Nichols. 2007. Modulation of lateral diffusion in the plasma membrane by protein density. Curr. Biol. 17:462-467. doi:10.1016/j.cub.2007.01.069

Greenberg, S., and S. Grinstein. 2002. Phagocytosis and innate immunity. Curr. Opin. Immunol. 14:136-145. doi:10.1016/S0952-7915(01)00309-0

Greenberg, S., P. Chang, and S.C. Silverstein. 1993. Tyrosine phosphorylation is required for $\mathrm{Fc}$ receptor-mediated phagocytosis in mouse macrophages. J. Exp. Med. 177:529-534. doi:10.1084/jem.177.2.529

Haugh, J.M., F. Codazzi, M. Teruel, and T. Meyer. 2000. Spatial sensing in fibroblasts mediated by $3^{\prime}$ phosphoinositides. J. Cell Biol. 151:1269-1280. doi:10.1083/jcb.151.6.1269

Herskovitz, B., D. Guerry IV, R.A. Cooper, and A.D. Schreiber. 1977. Effect of cytochalasin B on human monocyte binding and sphering of IgG-coated human erythrocytes. Blood. 49:289-294.

Hoppe, A.D., and J.A. Swanson. 2004. Cdc42, Rac1, and Rac2 display distinct patterns of activation during phagocytosis. Mol. Biol. Cell. 15:3509-3519. doi:10.1091/mbc.E03-11-0847

Jaqaman, K., D. Loerke, M. Mettlen, H. Kuwata, S. Grinstein, S.L. Schmid, and G. Danuser. 2008. Robust single-particle tracking in live-cell time-lapse sequences. Nat. Methods. 5:695-702. doi:10.1038/nmeth.1237

Jongstra-Bilen, J., R. Harrison, and S. Grinstein. 2003. Fcgamma-receptors induce Mac-1 (CD11b/CD18) mobilization and accumulation in the phagocytic cup for optimal phagocytosis. J. Biol. Chem. 278:45720-45729. doi:10.1074/jbc.M303704200

Just, I., G. Fritz, K. Aktories, M. Giry, M.R. Popoff, P. Boquet, S. Hegenbarth, and C. von Eichel-Streiber. 1994. Clostridium difficile toxin B acts on the GTP-binding protein Rho. J. Biol. Chem. 269:10706-10712.

Kovács, M., J. Tóth, C. Hetényi, A. Málnási-Csizmadia, and J.R. Sellers. 2004. Mechanism of blebbistatin inhibition of myosin II. J. Biol. Chem. 279:35557-35563. doi:10.1074/jbc.M405319200

Kress, H., E.H.K. Stelzer, D. Holzer, F. Buss, G. Griffiths, and A. Rohrbach. 2007. Filopodia act as phagocytic tentacles and pull with discrete steps and a load-dependent velocity. Proc. Natl. Acad. Sci. USA. 104:1163311638. doi:10.1073/pnas.0702449104

Mao, Y.S., M. Yamaga, X. Zhu, Y. Wei, H.Q. Sun, J. Wang, M. Yun, Y. Wang, G. Di Paolo, M. Bennett, et al. 2009. Essential and unique roles of PIP5Kgamma and -alpha in Fcgamma receptor-mediated phagocytosis. J. Cell Biol. 184:281-296. doi:10.1083/jcb.200806121

Marshall, J.G., J.W. Booth, V. Stambolic, T. Mak, T. Balla, A.D. Schreiber, T. Meyer, and S. Grinstein. 2001. Restricted accumulation of phosphatidylinositol 3-kinase products in a plasmalemmal subdomain during Fc gamma receptor-mediated phagocytosis. J. Cell Biol. 153:1369-1380. doi:10.1083/jcb.153.7.1369

May, R.C., E. Caron, A. Hall, and L.M. Machesky. 2000. Involvement of the Arp2/3 complex in phagocytosis mediated by FcgammaR or CR3. Nat. Cell Biol. 2:246-248. doi:10.1038/35008673

Mero, P., C.Y. Zhang, Z.Y. Huang, M.K. Kim, A.D. Schreiber, S. Grinstein, and J.W. Booth. 2006. Phosphorylation-independent ubiquitylation and endocytosis of Fc gammaRIIA. J. Biol. Chem. 281:33242-33249. doi:10.1074/jbc.M605372200

Michl, J., M.M. Pieczonka, J.C. Unkeless, G.I. Bell, and S.C. Silverstein. 1983. $\mathrm{Fc}$ receptor modulation in mononuclear phagocytes maintained on immobilized immune complexes occurs by diffusion of the receptor molecule. J. Exp. Med. 157:2121-2139. doi:10.1084/jem.157.6.2121

Newman, S.L., L.K. Mikus, and M.A. Tucci. 1991. Differential requirements for cellular cytoskeleton in human macrophage complement receptor- and Fc receptor-mediated phagocytosis. J. Immunol. 146:967-974.

Nichols, B.J., A.K. Kenworthy, R.S. Polishchuk, R. Lodge, T.H. Roberts, K. Hirschberg, R.D. Phair, and J. Lippincott-Schwartz. 2001. Rapid cycling of lipid raft markers between the cell surface and Golgi complex. J. Cell Biol. 153:529-541. doi:10.1083/jcb.153.3.529

Ninomiya, N., K. Hazeki, Y. Fukui, T. Seya, T. Okada, O. Hazeki, and M. Ui. 1994. Involvement of phosphatidylinositol 3-kinase in Fc gamma receptor signaling. J. Biol. Chem. 269:22732-22737.

Scott, C.C., W. Dobson, R.J. Botelho, N. Coady-Osberg, P. Chavrier, D.A. Knecht, C. Heath, P. Stahl, and S. Grinstein. 2005. Phosphatidylinositol4,5-bisphosphate hydrolysis directs actin remodeling during phagocytosis. J. Cell Biol. 169:139-149. doi:10.1083/jcb.200412162

Sheikh, S., W.B. Gratzer, J.C. Pinder, and G.B. Nash. 1997. Actin polymerisation regulates integrin-mediated adhesion as well as rigidity of neutrophils. Biochem. Biophys. Res. Commun. 238:910-915. doi:10.1006/ bbrc. 1997.7407

Sobota, A., A. Strzelecka-Kiliszek, E. Gładkowska, K. Yoshida, K. Mrozińska, and K. Kwiatkowska. 2005. Binding of IgG-opsonized particles to Fc gamma $\mathrm{R}$ is an active stage of phagocytosis that involves receptor clustering and phosphorylation. J. Immunol. 175:4450-4457.

Teruel, M.N., T.A. Blanpied, K. Shen, G.J.Augustine, and T. Meyer. 1999. A versatile microporation technique for the transfection of cultured CNS neurons. J. Neurosci. Methods. 93:37-48. doi:10.1016/S0165-0270(99)00112-0

van Zeijl, L., B. Ponsioen, B.N.G. Giepmans, A. Ariaens, F.R. Postma, P. Várnai, T. Balla, N. Divecha, K. Jalink, and W.H. Moolenaar. 2007. Regulation of connexin43 gap junctional communication by phosphatidylinositol 4,5bisphosphate. J. Cell Biol. 177:881-891. doi:10.1083/jcb.200610144

Várnai, P., and T. Balla. 1998. Visualization of phosphoinositides that bind pleckstrin homology domains: calcium- and agonist-induced dynamic changes and relationship to myo-[3H]inositol-labeled phosphoinositide pools. J. Cell Biol. 143:501-510. doi:10.1083/jcb.143.2.501

Vieira, O.V., R.J. Botelho, L. Rameh, S.M. Brachmann, T. Matsuo, H.W. Davidson, A. Schreiber, J.M. Backer, L.C. Cantley, and S. Grinstein. 2001. Distinct roles of class I and class III phosphatidylinositol 3kinases in phagosome formation and maturation. J. Cell Biol. 155:19-25. doi:10.1083/jcb.200107069 